\title{
Human Research Subjects As Human Research Workers
}

\author{
Holly Fernandez Lynch*
}

\begin{abstract}
:
Biomedical research involving human subjects has traditionally been treated as a unique endeavor, presenting special risks and demanding special protections. But in several ways, the regulatory scheme governing human subjects research is counter-intuitively less protective than the labor and employment laws applicable to many workers. This Article relies on analogical and legal reasoning to demonstrate that this should not be the case; in a number of ways, human research subjects ought to be fundamentally recast as human research workers. Like other workers protected under worklaw, biomedical research subjects often have interests that diverge from those in positions of control but little bargaining power for change. Bearing these important similarities in mind, the question becomes whether there is any good reason to treat subjects and protected workers differently as a matter of law. With regard to unrestricted payment, eligibility for a minimum wage, compensation for injury, and rights to engage in concerted activity, the answer is no and human subjects regulations ought to be revised accordingly.
\end{abstract}

* Executive Director, Petrie-Flom Center for Health Law Policy, Biotechnology, and Bioethics, Harvard Law School. J.D./M.Bioethics, University of Pennsylvania. My thanks to Glenn Cohen, Einer Elhauge, Carl Elliott, Jonathan Jay, Sophia Lee, Paul Lombardo, Kristin Madison, Michelle Meyer, Collin O'Neill, Ben Roin, Benjamin Sachs (HLS), Benjamin Sachs (NYU), Seema Shah, Jeff Skopek, and Patrick Taylor for very helpful comments and discussion. Thanks also to participants in the 2012 Harvard Law School Health Law Policy Workshop; the Petrie-Flom Center 2012 Conference on The Future of Human Subjects Research Regulation; and the American Society of Law, Medicine, and Ethics 2012 Health Law Professors Conference. Finally, thank you to Jordan Bachr and Afroditi Giovanopoulou, who provided research assistance, and the excellent editors of the Yale Journal of Health Policy, Law, and Ethics. 


\section{TABLE OF CONTENTS}

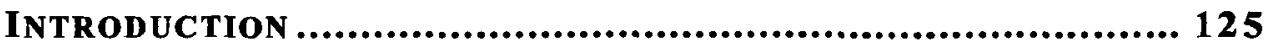

I. LEGAL AND ETHICAL REQUIREMENTS FOR HSR ................ 130

II. RESEARCH PARTICIPATION AS A JOB............................ 132

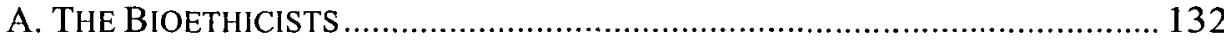

1. HEALTHY SUbJECTS AND AVOIDING EXPLOITATION ............................ 133

2. EQUATING SUBJECT PAYMENT WITH A WAgE..................................... 137

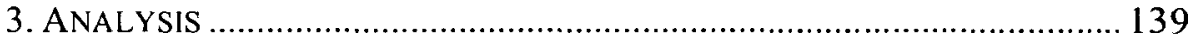

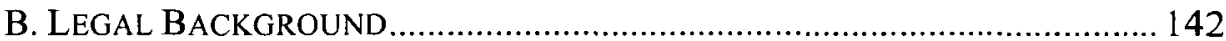

1. EMPLOYEES AND EMPLOYERS........................................................ 142

2. THE EMPLOYMENT Status OF HUMAN RESEARCH SUBJECTS............... 144

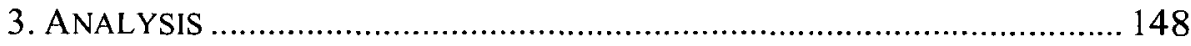

III. Clarifying the ANalogy and Its SCOPE ................... 149

A. WhY NOT APPLY WORKLAW DIRECTLY TO SUBJECTS? .......................... 149

B. SHARED CONCERNS OF SUBJECTS AND PROTECTED WORKERS ................ 151

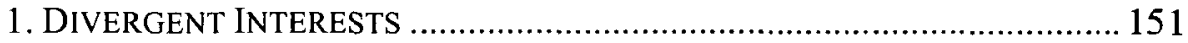

2. Bargaining Power, Collective ACtion, AND EXPloitation........ 152

3. Democratic Deficits, DEPENDENCY, AND THE NEED fOR PROTECTION 153

C. Weaker Analogy, Same Protections ................................................ 154

IV. LEVELING SUBJECTS UP TO WORKERS .......................... 156

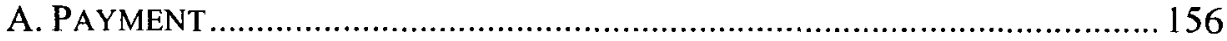

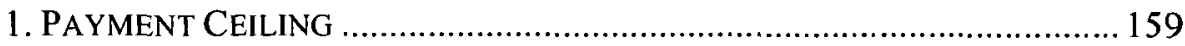

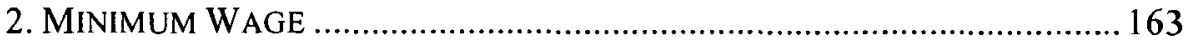

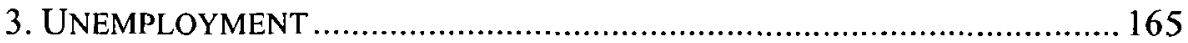

B. CARE AND COMPENSATION FOR INJURY ……........................................ 166

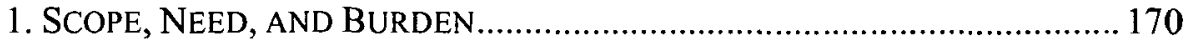

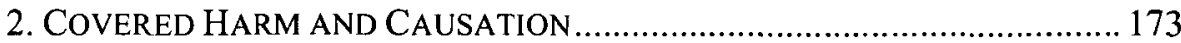

3. Funding, TORT PREEMPTION, AND AdDITIONAL CONCERNS................ 175 
4. UNPAID SUBJECTS ................................................................. 177

C. WORKING CONDITIONS AND INSPECTIONS ......................................... 179

D. COLLECTIVE BARGAINING AND UNIONS ........................................ 181

V. OUtSTANDING OBJeCtions ................................... 191

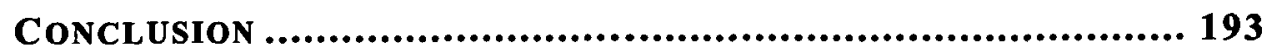




\section{INTRODUCTION}

In the early 1930s, a physician named William Osler Abbott was working to develop a new technique for rapidly intubating the human intestine. He swallowed the tubes himself until he "was sick of the sight of them" and worked out some aspects of the technique using hospital patients. Eventually, however, he realized the need to experiment on healthy human subjects.'

Abbott planned to offer two dollars a day to anyone willing to take the job, and expected no difficulty recruiting at the height of the Depression. However, relief administrators refused to refer anyone for this type of work. Abbott lamented that "[i]n that day of poverty, destitution and collapsing homes, not one solitary subject did I ever get through the very agencies that were apparently striving to find jobs, to make jobs, to beg jobs of any kind for hungry men." Abbott also failed to recruit "beggars," "tramps, vagrants, and the unemployed," all of whom recoiled at the work once it was described to them. Eventually, he enlisted the help of a "black janitor on the hospital floor," offering a finder's fee for every healthy subject brought in "appearing sober" and fasting, and finally had some success. ${ }^{2}$

As he prepared to exhibit the intubation technique at a medical conference, however, Abbott faced an unexpected problem: his subjects went on strike, seeking more money. At the eleventh hour, he managed to recruit new volunteers from a class of medical students, "a shipment of scab labor . . that would have made any factory foreman green with envy." Then, "the National Labor Relations Board being as yet unborn," Abbott "had the pleasure of indulging in a little old-fashioned capitalism. We fired the whole lot of [strikers], lock, stock and barrel. The exhibit went off like clockwork." ${ }^{3}$ Thereafter, Abbott began advertising in newspapers, which generated enough interest that he was able to have his pick from among the applicants, most of whom volunteered for financial reasons. ${ }^{4}$

Abbott's encounters are in many ways from a different time, but much of what he describes could apply equally well to biomedical research involving human subjects today: advertisements, payment for participation, and recruitment based on physical characteristics and willingness to cooperate. One key feature, however, stands in stark contrast. Abbott clearly viewed his subjects as workers and their research participation as a type of job. But this view of the subject has never taken hold. Today, researchers, ethicists, and regulators generally see subjects as a class unto themselves - a class in need of special protection as a

$1 \mathrm{~W}$. Osler Abbott, The Problem of the Professional Guinea Pig, 68 TransaCtions AM. Clinical \& Climatological Ass'N 1, 1 (1957).

$2 I d$ at $2-3$.

$3 \mathrm{Id}$. at 4.

$4 I d$. at 6-8. 
result of a history of research scandal and other supposedly unique characteristics, such as the nature of subjects' vulnerability, motivation, and risk taking.

As a result, the protections offered to many traditional workers under U.S. labor and employment law (hereinafter, "worklaw") have been treated as completely separate from and exclusive of the regulatory scheme governing clinical research. And although that regulatory scheme, and the thrust of research ethics in general, is heavily focused on subject protection, some traditional workers - usually those satisfying the legal definition of "employee" - receive a number of legal protections that research subjects do not.

In recent years, however, the idea of extending worker-type legal protections to human subjects has received some attention from bioethicists, and a few legal decisions have even treated subjects as employees. In fact, while the subject strike remains a novelty, the threat has been successfully leveraged at least once since Abbott's time by healthy subjects in a drug metabolism study in Philadelphia. ${ }^{5}$

These developments raise a number of interesting questions: In what ways are human subjects really like other workers? How are workers more protected than subjects, and when do the rationales for various worklaws fit the context of human subjects research (HSR)? Should human subjects be treated like employees, independent contractors, or volunteers, or is a more nuanced application of worker protections needed, if at all? Each of these questions is addressed in what follows, but a number of prefatory statements are in order.

First, although the overarching discussion may be relevant to the entire realm of HSR including social and behavioral research, primarily due to space constraints, the focus here will be limited to biomedical research - and more specifically, to clinical trials conducted in competent adult subjects.

In that context, this Article seeks to critically examine the way HSR is currently regulated and to challenge the status quo approach that treats subjects and workers as wholly distinct entities. Unlike much existing scholarship, ${ }^{6}$ however, it does not proceed by first identifying a variety of problems with the HSR regulations and then searching for analogous models from clinical medicine or elsewhere that potentially could be combined to do better; this is not an Article about the inadequacies of institutional review boards, the problems associated with poorly worded consent forms, or the inherent shortcomings of the HSR regime. In fact, in this Article, the question is not about better versus worse, adequate versus inadequate, good versus bad, but rather consistency versus inconsistency. Thus, the Article starts with the premise that subjects and protected workers are incredibly similar, and then uses that fundamental similarity to identify problems with the existing HSR regulatory structure -

5 Robert P. Helms, Human Guinea Pigs “Band Together" and Win a Pay Hike, GuINEA PIG ZERO (2003), http://www.guineapigzero.com/helmsstrike.html (last visited Nov. 21, 2013).

6 See infra Part II.A. 
aspects that are problematic by virtue of their inconsistency with the legal treatment of protected workers, and that could be rendered less problematic through a consistent approach. Thus, the scope of the question includes only subjects and traditional workers, not subjects and every other conceivable comparator. $^{7}$

Using this particular type of analogical methodology, the Article advances a simple argument: (1) Research subjects are, in relevant respects, like those workers entitled to the protections offered by worklaw. In the clearest cases, they are healthy, paid, and treat research participation as work. But even beyond that, with the exception of true altruists, all types of clinical research subjects share the key features that motivate worker protections, including interests that diverge from those in positions of control, poor bargaining power, and collective action problems. (2) Thus, the two groups should be treated alike unless there is some good reason to behave otherwise. At present, however, they are treated inconsistently and in both directions - subjects are simultaneously more and less protected than traditional workers (note that I did not say "better" and "worse," as that is a distinct normative inquiry). The former scenario is largely tabled for future work in order to permit sufficient attention to those circumstances in which subjects currently find themselves less protected than their counterparts in the working world. This is the more appropriate starting point given its contrast against the intense drive for subject protection that motivates both the existing legal and predominant ethical paradigms.

Of course, establishing a strong analogy between subjects and protected workers is only one step in the analysis; analogy alone cannot resolve the essential question of how to address inconsistent treatment between two similar points of comparison. Thus, it is also necessary to determine which side of the analogy should be destabilized in order to establish consistency - should we aim to level subjects up to workers, granting them new baseline protections that run alongside those they already have, or workers down to subjects, eliminating some of their current baseline entitlements?

To that point, there is substantial scholarly and social disagreement as to the value and importance of the minimum wage, workers' compensation, and union activities, for example, and certainly some abuses. Opponents of these worklaw protections maintain that they are blunt instruments for nuanced work

7 The worker comparison is chosen here primarily because it has been raised on numerous occasions in the bioethics literature, but has received insufficient legal attention. See, e.g., Paul McNeill, Paying People to Participate in Research: Why Not?, 11 BIOETHICS 390 (1997); Benjamin Sachs, The Exceptional Ethics of the Investigator-Subject Relationship, 35 J. MED. \& Phil. 64 (2010); Marx W. Wartofsky, On Doing It for Money, in NAT'L COMM. FOR THE Protection of Human Subjects of Biomedical and Behavioral Research, Appendix to RePORT AND ReCOMmEndations: ResearCh InVOLVIng PRISONERS (1976); and infra, Section II.A. However, selecting this analogy is not meant to foreclose others, such as comparisons to patients, investors, donors (of body parts, time, or money), surrogates, prostitutes, prisoners, soldiers, or even lab rats. 
relationships and the variety of workplaces covered and that they unjustifiably hinder the economy, such that we should instead leave everything to contract, relegating the terms and conditions of work to the market. Similarly, some have suggested a private ordering approach to certain aspects of HSR, ${ }^{8}$ allowing competent adult subjects to contract with researchers and sponsors for the benefits and protections they need to make research participation worthwhile.

However, for workers and subjects alike, there are reasons to be wary of a purely market-based approach. As we will see, both lack information available to the "opposing" party, both face substantial constraints on their bargaining power, and both are susceptible to other problems recognized by behavioral economists, such as weighting present interests more strongly than future interests and otherwise failing to act in full accordance with the "rational actor." These features also help to explain why, if subjects wanted or needed additional protections, they have not already attained them. ${ }^{9}$

Recognizing that this is a point of contention, this Article assumes (and I believe) that we ought to be extremely hesitant to scale back the hard-fought protections offered by worklaw and won over time by the labor movement. Leveling workers down is inadvisable, whereas leveling subjects up is consistent with the overall protective approach to HSR. To clarify the thesis, then, subjects and workers are like cases and subjects ought to be treated more like protected workers, unless the reasons for granting a particular type of worker protection fail to apply to research subjects. And because this Article tables the issue of whether subjects should retain those protections that are more extensive than those available to traditional workers, the focus here is on changes that would be additive to the status quo research regulations.

In setting forth this argument, the Article makes a number of unique contributions. It is the first to offer a comprehensive legal analysis of this analogy and the first to dig deeply into the question of why we protect workers the way we do in order to determine whether those reasons are similarly applicable to the subjects of biomedical research. It also offers new support for the argument against research exceptionalism (i.e., the idea that research is special), and sets a foundation for future applications of the worker analogy to determine the protections that ought to be extended to organ donors, surrogate parents, and the like.

With these broader goals in mind, the Article proceeds as follows: Part I provides brief background on the current regulations governing HSR, and identifies several reasons why these regulations evolved independent of worklaw. Part II then describes and critiques existing bioethical and legal analyses of the application of worker protections to subjects. Although these threads in the

8 See, e.g., Michelle N. Meyer, Regulating the Production of Knowledge: Research RiskBenefit Analysis and the Heterogeneity Problem, 65 ADMIN. L. REv. 237 (2013).

9 Another important possibility is simply that the model of subjects as unique has become so entrenched that subjects themselves have not generally thought to look to worklaw as a point of comparison. 
literature provide an important starting point, they fail to adequately acknowledge that workers are not a homogenous group, nor are they all entitled to legal protection. Thus, Part II endeavors to fill that gap by considering the different types of workers recognized by the law, the standards for distinguishing between them, and the reasons those distinctions matter. It concludes that at least some types of subjects, namely those who are healthy and paid to participate in nontherapeutic research, can almost certainly be legal employees - the most protected category - without changing a thing; this conclusion itself is an important and novel contribution to the literature, since it is decidedly not how subjects are treated at present.

However, Part III explains that simply treating subjects as employees would be less than ideal, as it would incorporate existing problems from worklaw into the research setting. Most importantly, the employee label currently fails to capture all workers in need of legal protection, and would similarly fail to include all subjects in need of worker protection. Thus, rather than analogizing to a flawed status quo, Part III explores the fundamental reasons that certain types of workers ought to be legally protected, many of which are sources of vulnerabilities shared by a variety of research subjects. Finally, this Part argues that even those subjects who do not closely resemble traditionally protected workers (i.e., those subjects who volunteer altruistically, for therapeutic benefits, or without pay) should nonetheless receive worker protections either because they cannot be reliably distinguished from other subjects or because they face the same relevant vulnerabilities.

From the starting point that workers should not be stripped of important protections, Part IV considers the remaining options of leveling subjects up or identifying relevant differences between the two groups. With regard to payment, it concludes that the current implicit limits on subject compensation are inappropriate and should be lifted, and that some subjects should be offered at least a modified minimum wage but not unemployment compensation. It argues that injured subjects should be guaranteed a no-fault remedy along the lines of the worker compensation system, with some adjustments regarding the types of injuries that will qualify. In contrast to regulation of the workplace, research site conditions are best handled by application and enforcement of existing building codes, facilities regulations, and the like. And although subjects are likely to face some difficulty joining together for collective bargaining and alternative approaches are likely to be more fruitful, they should be protected in their concerted activities and any attempts at unionization.

Finally, Part V briefly responds to a few outstanding objections, emphasizing the crucial point that protecting subjects like workers is not meant to encourage "professional guinea-pigging," but rather to ensure that like cases are treated alike. In the end, human research subjects ought to be fundamentally recast as human research workers. 


\section{LEGAL AND ETHICAL REQUIREMENTS FOR HSR}

There are many different types of human subjects research, and studies may be risky or less so, biomedical or behavioral, early or later phase, governmentfunded or private. There are also many different types of human subjects, who may be paid or unpaid, healthy or sick, vulnerable or less so. Nonetheless, with few exceptions, ${ }^{10}$ the regulations governing HSR do not differentiate on these grounds. Instead, the regulations generally cast a wide and undifferentiated net, protecting the many types of human subjects in the many types of research studies in two primary ways."

First, they require that researchers obtain and document subjects' consent to research participation under conditions that minimize the possibility of coercion or undue influence and after a number of specific disclosures. ${ }^{12}$ Second, in order for potential subjects to even be given the opportunity to participate, an Institutional Review Board (IRB) comprised of disinterested scientific and nonscientific members must first review and approve proposed research. More specifically, IRBs cannot allow research to proceed unless risks to subjects will be minimized and remaining risks are reasonable in relation to anticipated benefits to subjects or society; subject selection will be equitable; informed consent will be sought; data will be adequately monitored to ensure subject safety; subject privacy and confidentiality will be protected; and there will be sufficient protections for vulnerable groups. ${ }^{13}$ IRBs are the ultimate gatekeepers in the world of HSR, authorized to approve, require changes to, reject, suspend, or terminate research studies. ${ }^{14}$

This heavily protectionist approach to HSR is best understood in historical context as a response to a number of ethical scandals and human rights tragedies that have been well documented elsewhere, ${ }^{15}$ such as the Nazi experiments, Tuskegee syphilis study, and others. This helps to explain, at least in part, why the HSR regulatory scheme has evolved separately from worklaw as

10 Note that there are some specific regulatory requirements for research involving pregnant women, children, and prisoners. See, e.g., 45 C.F.R pt. 46, subparts B, C, D (2013); 21 C.F.R. pt. 50, subpart D (2013).

11 See 45 C.F.R. pt. 46 (the U.S. Department of Health and Human Services' version of the "Common Rule"); 21 C.F.R. $\S \S 50,56,312,601,812$ (the relevant FDA regulations). The Common Rule covers most federally funded HSR due to its adoption by a number of government agencies. See Federal Policy for the Protection of Human Subjects, U.S. DeP'T. OF HEALTH \& HUM. SERVICES (HHS), http://www.hhs.gov/ohrp/humansubjects/commonrule/index.html (last visited Nov. 21, 2013). Investigation of a product regulated by FDA will be subject to FDA's (very similar) regulations, potentially in addition to the Common Rule.

1245 C.F.R $\S \S 46.116-.117 ; 21$ C.F.R. $\S \S 50.20,50.25,50.27$.

1345 C.F.R. $\$ 46.111 ; 21$ C.F.R. $\S 56.111$. In addition to initial review of research, IRBs must also engage in continuing review at least annually. 45 C.F.R. $\S 46.109(\mathrm{e}) ; 21$ C.F.R. $\S 56.109(\mathrm{f})$.

1445 C.F.R. $\S \S 46.109$ (a), 46.113; 21 C.F.R. $\$ \$ 56.109(a), 56.113$.

15 See Advisory Comm. ON Human Radiation Experiments (ACHRE), Final Report 98104 (1995). Part I of the ACHRE report also includes a discussion of the historical evolution of the HSR regulatory regime. 
a non-work regime: the Nazi victims and Tuskegee subjects hardly resembled workers in the usual sense, but rather looked like victims of torture and patients who had been subject to exploitation and neglect. Of course victims and workers should be protected differently.

Another factor leading to this segregated approach is that the HSR regulations were built on a predominantly medical model. Physicians were the ones who "took the lead in drawing up rules of conduct for human subjects research, and they were concerned to make the rules consistent with medical ethics and comparatively unconcerned to create rules consistent with the rules we apply in nonmedical contexts." 16 As a result, investigators - like practicing physicians - have traditionally been expected to act protectively toward their subjects' interests as a matter of professional responsibility, ${ }^{17}$ in contrast to the often antagonistic relationship between management and labor. Moreover, the clinical context in which biomedical research takes place also seems to create an intuition that research participation cannot be work, such that worklaw approaches would be inapposite. ${ }^{18}$

In reality, doctors engaged in research have fundamentally different goals and responsibilities than doctors engaged in medical practice, but this distinction has taken a long time to take root and remains somewhat controversial. ${ }^{19}$ And even if one accepts that distinction, there is no consensus that research participation actually constitutes work, or that it should be treated as such. ${ }^{20}$ Ultimately, neither the victim model nor the clinical paradigm leaves much room for a labor approach to HSR, from either legal or clinical perspectives.

As noted above, one obvious result of the fact that participation as a human subject traditionally has been treated as outside the realm of worklaw is that subjects are protected in a number of ways that workers, and others engaged in

16 Sachs, supra note 7, at 76.

17 See, e.g., Moral Science: Protecting Participants in Human Subjects Research, Presidential Comm'N for the Study of Bioethical Issues (PCSBI) 9, 70-74 (Dec. 2011), http://bioethics.gov/sites/default/files/Moral\%20Science\%20June\%202012.pdf [hereinafter Moral Science] (recommending that human research protections be more explicitly understood as professional standards).

18 On the other hand, the subjects of prison research, also of critical interest in the 1960 s and ' 70 s when the foundation for the current regulations was laid, may have lent themselves more favorably to a work-based regulatory regime, considering that they were often healthy, paid for their participation, involved in commercial research, and in many cases signed waivers acknowledging research risks. See Valerie H. Bonham \& Jonathan D. Moreno, Research with Captive Populations: Prisoners, Siudents, and Soldiers, in The OXford Textbook OF CliniCaL RESEARCH ETHICS 461, 465 (Ezekiel J. Emanuel et al. eds., 2008). However, the unique nature of their institutional confinement and restrictions on free choice weakened any resemblance to traditional work.

19 See Howard Brody \& Franklin G. Miller, The Clinician-Investigator: Unavoidable but Manageable Tension, 13 KENNEDY INST. ETHICS J. 329 (2003); Sachs, supra note 7, at 76-77.

20 See McNeill, supra note 7, at 391. 
risky activities, are not. ${ }^{21}$ Indeed, we do not have IRBs to approve which lawful employment opportunities we may be offered, nor do the agencies responsible for occupational health and safety and avoidance of employment discrimination consider various factors that are part of IRBs' mandate, such as social value, nonphysical risks, fair distribution of burdens and benefits, and the like. Moreover, in most other realms of decision-making, we speak only of consent, which may often be implicit, not of explicit, written "informed consent." 22 There are a host of disclosures that must be made to employees regarding their rights and certain types of workplace hazards, but these pale in comparison to the requirements for research consent. ${ }^{23}$ These and other examples of research exceptionalism skewed toward heavy subject protection have received quite a bit of attention in the literature, alongside more and less convincing arguments regarding potential justifications, as well as calls for reform. ${ }^{24}$

The flip side, however, has received quite a bit less attention: to the extent that the HSR regulations take a protectionist approach, and to the extent that research subjects share important features with traditional workers, should the protections extended to subjects really be less stringent than those provided by worklaw? In many cases, the answer is no.

\section{RESEARCH PARTICIPATION AS A JOB}

\section{A. The Bioethicists ${ }^{25}$}

Although far from a movement, a few bioethicists have considered the protections offered by worklaw as they search for ways to improve flaws they have identified in the existing human subjects regulatory regime. ${ }^{26}$ One line of argument notes the potential benefits of a labor framework given the current state

21 Again, note that suggesting research subjects are more protected than others does not necessarily correspond to a normative judgment as to whether they are better protected.

22 Franklin G. Miller \& Alan Wertheimer, Preface to a Theory of Consent Transactions: Beyond Valid Consent, in The Ethics of Consent: THeory and Practice 80 (Franklin G. Miller \& Alan Wertheimer eds., 2010).

23 See, e.g., 29 C.F.R. $§ \S 500.75-76$ (2013) (describing disclosures that must be made to migrant agricultural and seasonal day-haul workers); 29 C.F.R. $\$ 1910.1200$ (2013) (OSHA's Hazard Communication Standard). Some have argued for expanding the use of mandatory disclosure in employment law. See, e.g., Cynthia Estlund, Just the Facts: The Case for Workplace Transparency, 63 STAN. L. REV. 351 (2011).

24 For example, Ben Sachs considers the ethical principles applicable to research subjects that are not applicable to employees and volunteers, but not the legal differences per se. Sachs, supra note 7. See also Miller \& Wertheimer, supra note 22, at 79-105; James Wilson \& David Hunter, Research Exceptionalism, 10 AM. J. BIOETHICS 45, 48-49 (2010) (and the related open peer commentaries in the American Journal of Bioethics, Vol. 10, No. 8 (Aug. 2010)).

25 Note that not all of the authors cited in this section would necessarily self-identify as bioethicists. However, that title is used as shorthand to refer to arguments that have been made outside of the legal sphere.

26 Ari VanderWalde \& Seth Kurzban, Paying Human Subjects in Research: Where Are We, How Did We Get Here, and Now What?, 39 J.L. MED. \& ETHICs 543, 553-55 (2011). 
of paid participation by healthy subjects, while another emphasizes the discrepancy between the treatment of subjects and other wage-earners, and considers the implications of a unified approach, without necessarily endorsing it. However, a number of critical questions remain.

\section{Healthy Subjects and Avoiding Exploitation}

One reason to adopt a labor approach for HSR is the simple fact that as a result of payment, at least some subjects view research participation as a job, ${ }^{27}$ and even those who do not may sometimes reasonably be viewed as selling their bodily services for money, just like other laborers.

In addition to reimbursement for out-of-pocket costs, subjects of all types may be given additional payment, characterized as compensation for time and inconvenience, an enrollment incentive, or even just a token of appreciation. ${ }^{28}$ However, whereas patient-subjects in a potentially therapeutic trial spanning the course of two years might receive between $\$ 25-50$ per monthly visit, healthy subjects in a phase I drug study lasting a few weeks might receive $\$ 200-400$ per day. ${ }^{29}$

The difference can be explained by the fact that for healthy subjects in nontherapeutic research, the risks and burdens of participation are not compensated by the prospect of direct medical benefit or even contribution to an area of personal relevance. Thus, substantial payments are often essential to adequate recruitment. ${ }^{30}$ However, it is worth noting that while research participation as a healthy subject may be unpleasant, it is not usually as risky as the general public perceives it to be. ${ }^{31}$ Subjects are closely monitored and serious adverse drug reactions are rare. Nonetheless, they do occur, certain types of

27 Roberto Abadie, The Professional Guinea Pig: Big Pharma and the Risky World of Human Subjects ResearCh 2, 78 (2010); Guinea PIg Zero: An ANTHOLOGy of The Journal for Human ReSEARCH SubJECTS 5-6 (Robert Helms ed., 2002); Matthew Weinstein, A Public Culture For Guinea Pigs: US Human Research Subjects After the Tuskegee Study, 10 SCIENCE AS CULTURE 195, 204 (2001); Nancy Ondrusek, Making Participation Work: A Grounded Theory Describing Participation in Phase I Drug Trials from the Perspective of a Healthy Subject 78-80, 178 (2010) (unpublished Ph.D. dissertation, University of Toronto) (on file with author).

28 See Terrence F. Ackerman, An Ethical Framework for the Practice of Paying Research Subjects, IRB: ETHICS \& HuM. RES., July-Aug. 1989, at 1, 2; Ruth W. Grant \& Jeremy Sugarman, Ethics in Human Subjects Research: Do Incentives Matter?, 29 J. MED. \& PHIL. 717, 719-23 (2004) (distinguishing between different types of payments).

29 ABADIE, supra note 27 , at 5, 13, 22-23, 93, 121. For more on subject payment rates, see Neal Dickert \& Christine Grady, Incentives for Research Participants, in THE OXFORD TEXTBOOK OF ClINICAL RESEARCH ETHICS, supra note 18, at 386, 394; Ondrusek, supra note 27, at 10.

30 Carl Elliott, Guinea-Pigging, NEW YORKER Jan. 7, 2008, http://www.newyorker.com/reporting/2008/01/07/080107fa_fact_elliott.

31 ABADIE, supra note 27, at 75; Trudo Lemmens \& Carl Elliott, Guinea Pigs on the Payroll: The Ethics of Paying Research Subjects, 7 ACCOUNTABILITY REs. 3, 13 (1999); David B. Resnick, Compensation for Research-Related Injuries, 27 J. LEG. MED. 263, 265 (2006). 
drugs may be riskier than others, ${ }^{32}$ and monitoring for the duration of a study will not catch any problems that manifest later. ${ }^{33}$ Unfortunately, there is little empirical data on the overall safety of participation as a healthy research subject. $^{34}$

As one might expect, like workers, many healthy subjects are motivated to participate in nontherapeutic clinical research primarily by economic factors, even if other reasons also play a secondary role. ${ }^{35}$ The money offered can be lucrative for relatively short spurts of commitment, leading some healthy subjects to become repeat players, ${ }^{36}$ although it is unclear precisely how large this subset is. In fact, both the numerator and denominator are relative unknowns because there are several barriers to developing accurate estimates of how many healthy subjects are enrolled in research overall, and how much of the demand for the healthy subjects is met by those who have participated before. There is no national registry of trial subjects, although some sites have developed local registries to address the problem of overlapping enrollment. For example, a group of five sites in Florida found that over the course of 18 weeks in 20092010,2081 individuals attempted to enroll in 27 Phase I studies, 2.4\% (50) of whom attempted to enroll in another study within 30 days of receiving a dose in a previous study, and an additional 8.9\% (186) attempted to enroll again within 60 days. ${ }^{37}$ Local registries obviously provide only a limited snapshot, however, and can be circumvented; ${ }^{38}$ the Florida cohort did not include two large research sites in the area. Thus, U.S. and worldwide numbers remain elusive, but the Florida data alone indicate that the overall number of healthy subjects is not trivial, and that the subset of repeat subjects is also substantial. In fact, there exists a small

32 Roberto Abadie, The Professional Guinea Pig, BIoEdGE (Sept. 14, 2010), http://www.bioedge.org/index.php/bioethics/bioethics_article/9204/.

33 ABADIE, supra note 27 , at 7-8, 82-83.

34 Adil E. Shamoo \& David B. Resnick, Strategies to Minimize Risks and Exploitation in Phase One Trials on Healthy Subjects, 6 AM. J. BIOETHICS, at W1, W4-W5 (2006).

35 Leanne Stunkel \& Christine Grady, More than the Money: A Review of the Literature Examining Healthy Volunteer Motivations, 32 Contemp. CliniCal Trials 342 (2011); see also ABADIE, supra note 27, at 5, 41; Ondrusek, supra note 27, at 178-79; Olivia Katrandjian, Growing Number of Mothers Participating in Clinical Trials to Make Ends Meet, ABC News (Nov. 21, 2011), http://abcnews.go.com/Health/growing-number-mothers-participating-clinical-trials-makeends/story?id=14999849. For a description of the type of people who typically become healthy research subjects, see ABADIE, supra note 27, at 32; GUINEA PIG ZERO, supra note 27, at 212-214; Sheldon Zink, Maybe We Should Pay Them More, 1 AM. J. BioETHICs 88, 88 (2001); Elliott, supra note 30 .

36 See ABADIE, supra note 27, at 66; Shamoo \& Resnick, supra note 34, at W3; Ondrusek, supra note 27 , at 5 .

37 Darran Boyar \& Norman M. Goldfarb, Preventing Overlapping Enrollment in Clinical Studies, J. Clinical Res. Best Practices 2 (Apr. 2010), http://firstclinical.com/journal/2010/1004_ClinRSVP.pdf; see also Giovan Maria Zanini \& Claudio Marone, A New Job: Research Volunteer?, 135 SwISS MED. WKLY. 315, 315-317 (2005) (reporting similar results from a Swiss register of healthy subjects).

38 David B. Resnick \& Greg Koski, A National Registry for Healthy Volunteers in Phase 1 Clinical Trials, 305 JAMA 1236, 1237 (2011). 
community of individuals who view themselves as "professional guinea pigs,",39 some of whom have been able to turn participation into their livelihood. ${ }^{40}$

The increasing commercialization of clinical research over the past several decades, particularly at the early phases, ${ }^{41}$ combined with the motivations, perspectives, and behaviors of healthy participants in nontherapeutic research has led some to call for regulatory changes that would more accurately reflect this current state of affairs. Trudo Lemmens and Carl Elliott, for example, are troubled by the failure of regulatory and ethical guidelines to recognize that a great deal of research involving healthy subjects is essentially a business transaction. They argue that even though everyone knows better, "researchers have to pretend that [healthy] subjects are motivated by something other than money. ${ }^{[42]}$ Research subjects cannot negotiate payment, since payment is not supposed to be the focus of the transaction. Local research ethics boards are expected not to determine what is fair, but what is "undue inducement" per the regulations. ${ }^{43}$ The result is that healthy subjects face exploitation due to being essentially prohibited "from receiving a fair wage and denie[d] . . . the legal resources available to other high risk workers." "get none of the rights or benefits that come with a good job, such as workers' compensation, the right to unionize, disability benefits, or health insurance". 45

Reasoning that healthy and patient subjects have different interests, vulnerabilities, and motivations for participating, Lemmens and Elliott maintain that it is a mistake not to distinguish between them. ${ }^{46}$ They suggest that a labor

39 See, e.g., ABADIE, supra note 27; GuINEA PIG ZERO, supra note 27; Helms, supra note 5; Ondrusek, supra note 27. Note also that the "professional" subject in existence today is a far cry from the ideal form suggested by Maureen Rist and William J. Mohan in Wanted: Professional Research Subjects; Rewards Commensurate with Risks, 6 HASTINGS CENTER REP. 28 (1976).

40 Elliott, supra note 30 . Some subjects rely on research for a substantial proportion of their income, while others use the money as a needed supplement to cover bills or provide extra cash. See ABADIE, supra note 27, at 5, 32, 42; Ondrusek, supra note 27, at 72-75, 106, 172.

41 Richard Rettig, The Industrialization of Clinical Research, 19 HEALTH AFF. 129 (2000); Miriam Shuchman, Commercializing Clinical Trials - Risks and Benefits of the CRO Boom, 357 NEW ENG. J. MED. 1365 (2007); Elliott, supra note 30.

42 However, federal regulators are beginning to soften on the hard line they have historically drawn regarding financial motives for participating in research. See, e.g., Office of Human Research Protections (OHRP), Informed Consent: Frequently Asked Questions, HHS (Mar. 2011), http:/www.hhs.gov/ohrp/policy/consentfaqsmar2011.pdf [hereinafter OHRP, Informed Consent] (noting in response to Question 7 that "compensation may be an acceptable motive for agreeing to participate in research").

43 Trudo Lemmens \& Carl Elliott, Justice for the Professional Guinea Pig, 1 AM. J. BIOETHICS 51, 52 (2001).

$44 \mathrm{Id}$. at 53 .

45 Carl Elliott \& Roberto Abadie, Exploiting a Research Underclass in Phase 1 Clinical Trials, 358 NEw ENG. J. MED. 2316, 2317 (2008).

46 Savulescu also takes issue with the payment structure of clinical research, but without distinguishing between healthy and patient subjects. Instead, he distinguishes between commercial and noncommercial research, arguing that subjects should be offered "fair compensation and 
model is more appropriate for paid healthy subjects research, which takes place in a commercial sphere where the research institution and subject enter the relationship on financial grounds in the absence of shared interests. ${ }^{47}$ Indeed, they suggest that "the regulatory regime and protective measures offered by many labor and occupational health and safety laws may provide a very useful model for the protection of subjects" in a number of ways:

For example, labor-type legislation could empower occupational health and safety agencies to conduct inspections, and it could lead to the establishment of occupational health and safety committees in which subjects are represented.... Collective negotiations and unionization would be a way of empowering subjects and of giving them a stronger voice in arguing for good working conditions. As with workers' compensation, appropriate compensation schemes could be enforced to offer some form of financial security in case subjects are harmed in research. Standards of remuneration could be negotiated, based on the level of discomfort, the number and types of procedures, the duration of the studies, particular circumstances such as the obligation to remain in the research institution for a lengthy period of time, and so on. Regulation could also require ... that research subjects have disability insurance and other insurance coverage to protect them in cases of "occupational injury.",48

Lemmens and Elliott claim that action is needed on these fronts, since research participation is not considered "employment" at present, leaving subjects ineligible for the resources and protection provided by existing worklaws. ${ }^{49}$ However, they are careful to clarify that their linkage between healthy subjects research and labor contracts is not intended to be literal, emphasizing that "research has particular characteristics which warrant treating it as a category sui generis". 50 They also raise some additional concerns suggesting that they do not fully buy into the analogy, not all of which are convincing. For example, they worry about the risk of further commercializing healthy subjects research, exacerbating the risk of exploitation if restrictions on payment are

salary" when they participate in a project intended to bring in profit. Julian Savulescu, On the Commercial Exploitation of Participants of Research, 23 J. MED. ETHICs 392 (1997).

47 Lemmens \& Elliott, supra note 31, at 4-5, 14-16. Many authors have argued for differential treatment of healthy subjects and patient subjects. See Lemmens \& Elliott, supra note 43, at 52; Ari VanderWalde, Undue Inducement: The Only Objection to Payment, 5 AM. J. BIOETHICS 25, 26-27 (2005); Ondrusek, supra note 27, at 197.

48 Lemmens \& Elliott, supra note 31, at 16-17.

49 Lemmens \& Elliott, supra note 43, at 52.

50 Lemmens \& Elliott, supra note 31, at 16. 
removed without adding other protections (particularly for safety), and potentially hindering important research that cannot afford to pay subjects a competitive price. ${ }^{51}$ Several of these issues are taken up in Part IV.A.

Other bioethicists have taken a similar stance with regard to advocating for certain employment-type protections of healthy Phase I research subjects, but have gone even further. For example, Adil Shamoo and David Resnick also argue against payment limits for healthy subjects, ${ }^{52}$ and suggest that these subjects, "like all workers," should receive compensation for injury and be permitted to use collective bargaining to negotiate for higher pay and better working conditions. Unlike Lemmens and Elliott, however, Shamoo and Resnick seem to have no reservations regarding the wholesale adoption of a labor approach to healthy subjects research. The same is true of Roberto Abadie, who rather than drawing a mere analogy to work, suggests that in order to avoid unacceptable exploitation we "need to recognize that [healthy] volunteers' participation is labor, even if it is what they call a 'weird type of work,' and provide better working conditions and proper compensation." 53 "Paid subjects," he maintains, "should be given the same labor protections guaranteed to other workers in risky occupations." 54

\section{Equating Subject Payment with a Wage}

Exploration of work-type protections for HSR has also been prompted by a different starting point, a widely discussed proposal by Neal Dickert and Christine Grady to treat payment to research subjects as a wage. Recognizing that paid participation raises a variety of ethical concerns, but also that payment is common, probably necessary in some cases, and currently without adequate regulatory guidance, Dickert and Grady set forth three models on which payment to healthy and patient-subjects could conceivably be based..$^{55}$ After rejecting both a market model, in which supply and demand for subjects dictate how much they are paid, and a reimbursement model, in which payment is limited to either reimbursement of a subject's actual expenditures or his time away from work, Dickert and Grady ultimately endorse a wage-payment model on the basis that research participation is analogous to other essential but unskilled labor, and should be paid on a commensurate scale. While recognizing some drawbacks, they favor this as the best option because it would reduce the possibility that subjects will be unduly induced to participate against their better judgment, as

51 Lemmens \& Elliott, supra note 43, at 52-53; see also Neal Dickert \& Christine Grady, What's the Price of a Research Subject? Approaches to Payment for Research Participation, 341 NEw ENG. J. MED. 198, 199-201 (1999) (rejecting the market model).

52 Shamoo \& Resnick, supra note 34, at W9-W11 (2006); see also VanderWalde, supra note 47, at 27 .

53 ABADIE, supra note 27 , at $165-66$ (emphasis added).

54 Id.

55 Dickert \& Grady, supra note 51, at 198. 
well as reduce the financial sacrifice required of subjects, while allowing them to be paid for work that is valuable to society. In addition, this approach would set a lower limit on the amount paid with all the associated benefits of a minimum wage, and the standardization of pay across studies would result in less competition for subjects between them. ${ }^{56}$

Despite this conclusion, however, Dickert and Grady did not suggest that a labor approach to research is appropriate across the board. James Anderson and Charles Weijer, on the other hand, have considered the moral implications of treating subjects as wage-earners or entrepreneurs on a broader scale. ${ }^{57}$ They note that if participation is a job for which one may be paid, morally indistinguishable from other lines of legitimate employment, then similar cases must be treated similarly, ${ }^{58}$ and the ethics of research participation must be viewed through the same moral lens used to determine just working conditions in other contexts. ${ }^{59}$

Anderson and Weijer suggest that management's obligations to workers vary depending on whether the workers are part-time or full-time, temporary or "career," and that these distinctions are mirrored among human subjects, who may be characterized as either "occasional" or "professional." explore the potential features of just working conditions, including those minimum protections set by law, as well as additional normative requirements such as the right to meaningful work and the fair distribution of "hard work." Anderson and Weijer recognize that each of these rights does not necessarily apply to all workers, but rather depends on their level of dependency, commitment, and investment.

Thus, like both temporary and career workers do, both occasional and professional subjects have a right to at least a minimum wage. ${ }^{62}$ Both are protected by standard work week legislation and have a right to overtime pay for hours outside of that standard. Both have a right to a safe workplace, and no fault compensation for work related injury. And both have the right to organize into unions. Similarly, professional subjects, like career workers, [also] have a right to a pension, to benefits such as

$56 I d$. at $199-201$.

57 James A. Anderson \& Charles Weijer, The Research Subject as Entrepreneur, 1 AM. J. BIOETHICS 67 (2001) [hereinafter Anderson \& Weijer, Entrepreneur]; James A. Anderson \& Charles Weijer, The Research Subject as Wage Earner, 23 TheORETICAL MED. \& Bioethics 359 (2002) [hereinafter Anderson \& Weijer, Wage Earner].

58 Anderson \& Weijer, Wage Earner, supra note 57, at 360.

59 Charles Weijer, Meaningful Work as Due Inducement, 26 THEORETICAL MED. \& BIOETHICS 431-32 (2005).

60 Anderson \& Weijer, Wage Earner, supra note 57, at 361-62.

$61 \mathrm{Id}$. at $364-70$.

$62 \mathrm{Id}$. at 375 . Anderson and Weijer appropriately take issue with Dickert and Grady's suggestion that subject payment should be kept low. 
medical and dental insurance, and finally, they have the right to meaningful work. ${ }^{63}$

Of course, at present, subjects are not treated this way, but rather "many of the deplorable working conditions characteristic of the industrial revolution are being duplicated in the realm of biomedical research."

This disparity is problematic and unjust, Anderson and Weijer maintain, if subjects are workers too. ${ }^{65}$ Thus, we must either adjust present practice or reject the idea of paid subjects as unskilled wage-earners. ${ }^{66}$ They do not explicitly state which approach they favor, although they do suggest some discomfort with treating research subjects like other workers and indicate that the morally satisfactory solution to the issue of subjects-for-hire requires something more than improved working conditions or unionization. ${ }^{67}$ Others, however, maintain that "paid research subjects must have the same rights, benefits, and payment schemes available to all workers of similar type.,"

\section{Analysis}

Although the bioethics literature considering the analogy between human subjects and more traditional workers has certainly moved the ball forward, the arguments remain incomplete. This is understandable given that the existing literature begins from a different starting point, using the analogy to identify solutions to imperfect subject protections, whereas this Article is more interested in the analogy for its own sake to identify inconsistencies in need of resolution. So what work remains?

First, while there has been some attempt to differentiate between different types of subjects and recognition of the fact that different types of workers generally get different rights and benefits, the distinctions that have been drawn by references to high-risk work, "good" jobs, and temporary versus career work do not necessarily map onto the lines drawn by the law, which predominantly distinguishes between independent contractors and employees. Many have criticized these legal lines and how they are drawn, as described below, but the fact remains that there are entire categories of workers who stand without the protections under discussion for subjects. The case has not yet been adequately made as to why subjects are distinguishable from independent contractors, who do not receive these protections, and analogous to employees, who do.

$63 \mathrm{Id}$. at 371 .

64 ld. at 372.

65 Anderson \& Weijer, Entrepreneur, supra note 57, at 68.

66 Anderson \& Weijer, Wage Earner, supra note 57, at 374.

67 Anderson \& Weijer, Entrepreneur, supra note 57, at 68; Weijer, supra note 59, at 432.

68 VanderWalde \& Kurzban, supra note 26, at 555. 
Another aspect of the debate that is far from resolved is whether human subjects actually engage in work. A number of potentially relevant criteria have been raised to date, including payment, and more specifically payment as a wage or something else $;{ }^{69}$ subject motivation and source of vulnerability; ${ }^{70}$ acting versus being acted upon, ${ }^{71}$ commodification of the body itself compared to sale of a service ${ }^{72}$ risk and uncertainty as key features of the activity or mere byproducts $;^{73}$ and the perceptions of relevant players. ${ }^{74}$ Resolution of this question in favor of participation as work would certainly strengthen the argument regarding subject protection, at least as a matter of consistency. However, given the philosophical complexity of accurately defining work, and because the argument regarding subject protection can also be made on the basis of analogy and shared goals and challenges, rather than on a definitional basis, the ontological question will not be further considered here. ${ }^{75}$

But note that some have even rejected the very analogy that would compare research participation to work, or have at least questioned the analogy's application. For example, when commissioned for comment on the issue by the National Commission for the Protection of Human Subjects of Biomedical and Behavioral Research, philosopher Marx Wartofsky argued that what is being sold by the research subject is different than what is being sold by the worker in a hazardous occupation; " $[t]$ he coal miner is paid to mine coal," he claimed, but the subject is "paid to put himself at risk in order to see what the effects will be on his body or his health." ${ }^{76}$ This distinction fails, however, because in both cases individuals are intentionally exposed to the risk of harm in order to achieve some other goal. More simply, the subject could just as easily be seen as paid to provide data - the primary purpose of HSR - as to accept risk, rendering risk a byproduct rather than a defining feature of research.

On the other hand, for certain types of research, such as challenge studies involving intentional exposure to infection and drug safety studies in healthy subjects, and for many types of research procedures done exclusively to gather research data, the primary goal of generating generalizable knowledge can only be achieved through the means of intentionally inflicting harm, rather than merely foreseeing it as a side effect. This is different from nearly every other

69 See, e.g., Lemmens \& Elliott, supra note 31; Anderson \& Weijer, Wage Earner, supra note 57; Grant \& Sugarman, supra note 28.

70 See, e.g., Lemmens \& Elliott, supra note 31, at 14-15; Shamoo \& Resnick, supra note 34.

71 See, e.g., Lemmens \& Elliott, supra note 31; Wartofsky, supra note 7.

72 See, e.g., Dickert \& Grady, supra note 51; Lemmens \& Elliott, supra note 31, at 16; Wartofsky; supra note 7.

73 See, e.g., Lemmens \& Elliott, supra note 31, at 16; Wartofsky, supra note 7.

74 See, e.g., Lemmens \& Elliott, supra note 31.

$75 \mathrm{I}$ do hope to address it in future scholarship, however. For now, suffice it to say that if prostitution and modeling can be considered work, participation as a human research subject can be as well. See Gregor Gall, Sex WORKER Union Organising: AN INTERNATIONAL STUDY, 23-34 (2006).

76 Wartofsky, supra note 7 , at 3-11 to 3-12. 
type of risky work in which harm may be foreseen, but is neither intended nor useful toward any goal, and in fact, hopefully avoided ${ }^{77}$ This distinction may be important with regard to justifying the special extra protections that are extended to research subjects, such as IRB review and informed consent. However, it certainly does not suggest that subjects should have fewer protections than workers or that it is inherently problematic or offensive to analogize between the two.

Nonetheless, Paul McNeill also maintains that risky work is a poor analogy to HSR, arguing that dangerous work "must be justified by some greater need" and "every effort should be taken to minimize the risks inherent in the work." 78 Although this is precisely what is required of HSR, and in fact not required in practice or by law for many types of work (such as crab fishing or diamond mining), McNeill questions whether research actually needs to be done at all, since progress is an "optional goal" and the "justification for research is always in terms of progress." 79 However, if dangerous work such as fire fighting is necessary, which McNeill concedes, why is dangerous work such as research participation - which may also save lives and meet basic human needs - any less so? There seems to be no reason to distinguish between different types of potentially preventable deaths when people have voluntarily put themselves at risk in the service of a greater good. Terrence Ackerman also tries to distinguish research from risky work, arguing that the "roles performed by police officers, fire fighters, and soldiers are absolutely essential to the welfare of society. ... By contrast, conduct of clinical research involving serious dangers to the welfare of subjects (which they would otherwise avoid) is generally not necessary to achieve the goals of medical research." ${ }^{80}$ If serious dangers to subject welfare in any particular study were not actually necessary to the research, however, IRBs would by regulation be required not permit them. Thus, Ackerman's distinction fails as well.

There may in fact be some real differences between at least certain types of research participation and traditional work, but none of these differences suggest that worklaw protections would be inappropriate in the research context, and the analogy is strong enough on its face to sustain serious comparative analysis. The bioethicists who have put the analogy forth to date, however, have not adequately considered the goals and rationales of worklaw and whether they overlap with those of human subjects protection. This is primarily because the bioethicists have identified some problematic aspects of the existing human subjects protection regime and seek lessons from other areas as to how things could be improved. In that context, all one needs to know is whether worklaw approaches

77 Thank you to Collin O'Neil for pointing out this distinction.

78 McNeill, supra note 7, at 392.

$79 \mathrm{Id}$.

80 Ackerman, supra note 28, at 4 . 
would in fact offer such improvement. But again, the problem motivating this Article is not some concern that the HSR regulations are inadequate, but rather concern that the HSR regulations are inconsistent. And for that type of analysis, a deeper understanding of why certain workers are protected in certain ways is essential to demonstrating that such inconsistency ought to be resolved.

\section{B. Legal Background}

Before getting to the question of "why," however, we must address some foundational questions regarding the type of worker most appropriate for comparison to human subjects.

\section{Employees and Employers}

Whether at the federal, state, or local level, the laws that regulate working relationships generally cover employees only, as opposed to independent contractors or volunteers. ${ }^{81}$ Thus, non-employees are usually ineligible for wage and hour protections, unemployment benefits, workers' compensation, family and medical leave, protected rights to form or join a union and collectively bargain, anti-discrimination and anti-retaliation protections, and workplace safety protections, for example. But who counts as an employee?

Worklaw statutes themselves often contain a number of specific inclusions and exclusions that help clarify whether a given worker can claim coverage. With regard to the definition of employee itself, however, statutory language is notoriously tautological. For example, the Occupational Safety and Health Act covers "employees," but defines the term as "an employee of an employer who is employed in a business of his employer which affects commerce," and an "employer" as a "person engaged in a business affecting commerce who has employees . . ." Similar circularity is found in the National Labor Relations Act, ${ }^{83}$ and a number of other federal and state laws. ${ }^{84}$ As a result, courts and administrative agencies have had to develop a number of tests for distinguishing employees from other types of workers.

One way to defeat employee status is to find that the work in question is beyond the economic or market sphere, such as that done in the home or by prisoners. ${ }^{85}$ Another is to determine that the worker is a volunteer because he

81 Richard R. Carlson, Why the Law Still Can't Tell an Employee When It Sees One and How It Ought to Stop Trying, 22 Berkeley J. LAB. \& EMP. L. 295, 366 (2001); Noah D. Zatz, Working Beyond the Reach or Grasp of Employment Law, in THE GlOves-OfF ECONOMY: WORKPLACE STANDARds at THE BotTom of America's Labor Market 31, 34 (Annette Bernhardt et al. eds., 2008).

8229 U.S.C. $\S 652(5)-(6)(2006)$.

8329 U.S.C. $\$ 152(2)-(3)(2006)$.

84 Carlson, supra note 81 , at 296, n.5.

85 Noah D. Zatz, Working at the Boundaries of Markets: Prison Labor and the Economic Dimension of Employment Relationships, 61 VAND. L. REV. 857, $861-62$ (2008). 
receives - and expects to receive - no financial compensation or benefits in return for his work. ${ }^{86}$ The receipt of certain benefits may push a worker out of volunteer territory, ${ }^{87}$ but mere reimbursement of expenses incurred incidental to the work is likely insufficient to do so.

Employee status also may be defeated by demonstrating that a worker is an independent contractor, but unfortunately, there is substantial uncertainty and disagreement regarding exactly how and when to make this distinction. The precise rules and definitions provided in statutes, regulations, and judicial opinions are usually both complex and vague. ${ }^{88}$ Courts have relied on a number of different approaches, including the common law "direct and control test" (which asks whether the hiring party retains the right to direct and control "not only what shall be done, but how it shall be done"); ${ }^{89}$ the "economic realities test" (which examines the whole activity of the relationship to determine the extent of the hiring party's domination over the worker and the worker's economic dependence); $;{ }^{90}$ and the "statutory purpose test" (which defines employees "in light of the mischief to be corrected and the end to be attained" by the law in question). ${ }^{91}$ A great deal has been written about the similarities and differences between each of these approaches, ${ }^{92}$ and certain tests have been adopted over others in the context of interpreting particular statutes. The important thing, however, is that in nearly every jurisdiction and for nearly every worklaw, the relevant test of employee status involves an intricate weighing of a laundry list of case-specific factors, which often point - or can be manipulated in different directions. ${ }^{93}$ As a result, these tests, which apply precisely as a result of statutory ambiguity, are often ambiguous themselves, leaving substantial room for unpredictability, confusion, and differences of opinion about the status of

86 Mitchell H. Rubinstein, Our Nation's Forgotten Workers: The Unprotected Volunteers, 9 U. PA. J. LAB. \& EMP. L. 147, 154 (2006).

87 Id. at 157; Zatz, supra note 85, at 920 n.293.

88 Zatz, supra note 81 , at 35.

89 Singer Mfg. Co. v. Rahn, 132 U.S. 518, 523 (1889); see also Carlson, supra note 81, at 304-306, 309-11; Katherine V.W. Stone, Legal Protections for Atypical Employees: Employment Law for Workers Without Workplaces and Employees Without Employers, 27 BERKELEY J. EMP. \& LAB. L. 251, 280 (2006); Zatz, supra note 81, at 35.

90 Carlson, supra note 81 , at $311-13,314,317,327,342$; Stone, supra note 89 , at 280; Zatz, supra note 81 , at 35 .

91 N.L.R.B. v. Hearst, 322 U.S. 111, 124 (1944) (quoting South Chicago Coal \& Dock Co. v. Bassett, 309 U.S. 251, 259 (1940)). For a discussion of the current status of the statutory purpose test, compare Carlson, supra note 81 , at $333,338,343,353$ and Zatz, supra note 81 , at 35 (suggesting that the test is essentially dead as a matter of determining federal statutory coverage), with Kenneth G. Dau-Schmidt \& Michael D. Ray, The Definition of "Employee" in American Labor and Employment Law, JAPAN INST. LAB. POL'Y \& TRAINING 124, http://www.jil.go.jp/english/events_and_information/documents/clls04_dauschmidt2.pdf (last visited Nov. 21,2013 ) (indicating that in most areas of worklaw, status as an employee is defined according to the purposes of the statute).

92 See, e.g., Carlson, supra note 81, at 309-44.

93 Id. at 343 . 
workers who seem to fall somewhere between employee and independent contractor (or volunteer). ${ }^{94}$

It is also important to recognize that there is a second component to determining a worker's employment status: identifying which party, if any, will ultimately be responsible for providing the benefits or protections afforded to employees under various laws. On the upside, the law recognizes joint employment relationships in which a single employee can simultaneously have multiple employers for the purposes of particular work ${ }^{95}$ However, there is also a growing phenomenon of "employerless employees"96 and "disintegrating employers." When there are multiple parties involved, the features of an employment relationship that usually hang together may be split up. ${ }^{98}$ As a result, each of the putative employers can plausibly deny employer status on the grounds that none individually satisfies the relevant legal criteria. Thus, a worker who does not really control his own work without dependence on any other party may be left without any employer from whom he could demand benefits.

\section{The Employment Status of Human Research Subjects}

Some of the shortcomings of worklaw categories and tests are apparent even from consideration of the limited instances in which the status of human subjects has been given direct legal attention. For example, in one of the more interesting opinions issued to date, an unemployment board of appeals relied on the intervention of a contract research organization (CRO) between the company seeking data and subjects participating in drug absorption trials to find that the subjects seeking benefits were independent sub-contractors, rather than employees. ${ }^{99}$ Importantly, CROs, which can take on any or all of a sponsor's regulatory obligations, and perform services ranging from recruitment to actually running trials in their own dedicated facilities, are increasingly being utilized to carry out clinical studies quickly and efficiently, ${ }^{100}$ rendering subjects' employment status even more precarious.

The state unemployment law in question defined workers as independent contractors ineligible for coverage when they satisfied a three-pronged test, ${ }^{101}$

94 Stephen D. Befort, Revisiting the Black Hole of Workplace Regulation: A Historical and Comparative Perspective of Contingent Work, 24 BERKELEY J. EMP. \& LAB. L. 153, 167 (2003); Carlson, supra note 81, at 301, 335-53.

95 Zatz, supra note 81 , at 41 .

96 See generally Stone, supra note 89.

97 Zatz, supra note 81 , at 37.

98 Richard R. Carlson, Variations on a Theme of Employment: Labor Law Regulation of Alternative Worker Relations, 37 S. TEX. L. REV. 661, 688-91 (1996).

99 Board of Appeals Decision, [Md.] Unempl. Ins. Rep. (CCH) If 8469 (Nov. 14, 1994), 1994 WL 16865552.

100 Phillip Mirowski \& Robert Van Horn, The Contract Research Organization and the Commercialization of Scientific Research, 35 SOC. STUD. SCI. 503, 509-13 (2005).

101 MD. CODE. ANN., LAB. \& EMPL. § 8-205 (West 1991). 
which the Board determined to be met here. First, the Board held that none of the control exerted by the CRO, Pharmakinetics, over the subjects was adequate to create an employer-employee relationship. The Board explained that when a general contractor hires a sub-contractor, the sub-contractor is not entirely unrestricted in his work, but rather must follow the set of plans established by the customer. Because these restrictions are imposed by the customer, however, they do not constitute an employer's control by the general contractor, even when he takes steps to ensure they are met. ${ }^{102}$ In the research context, then, the Board construed the drug company as the customer, the research protocol as the customer's plans, Pharmakinetics as the general contractor, and the subject as the sub-contractor. ${ }^{103}$ It also suggested that because after the subject ingests the drug, "it is his/her body which is actually performing the work," the general contractor cannot "logically" have control over the performance of the subject's work and can rather only monitor for proper administration. ${ }^{104}$

With regard to the second prong, customary engagement in the independent performance of the work involved, the Board maintained that the subjects were "engaged in the business of providing drug testing services," and emphasized that they may be involved in multiple studies for multiple companies. ${ }^{105}$ Third and finally, the Board had to decide whether the subjects' work was outside the usual course of Pharmakinetics' business, which it determined to be analyzing data on drug absorption and providing results to companies; "[t]esting drugs is merely the part of their business in which they derive their data." 106 On the other hand, it found that the work of the subjects is to test the drugs - to ingest them and provide bodily fluids for analysis. ${ }^{107}$ The subjects' work was clearly integral to Pharmakinetics' business, but the Board held it was nonetheless outside its scope, arguing that just as Pharmakinetics needs subjects, "the presence of a subcontractor plumber is needed and necessary in the course of business of his/her general contractor."

Although it emphasized the general contractor/sub-contractor analogy, it is noteworthy that at least the second and third prongs of the Board's (questionable) analysis would similarly apply had a drug company engaged the subjects for a test they were running themselves without the aid of a CRO. Nonetheless, the Board's analogy between a protocol and a customer's plans seems flawed. Plans may specify certain standards and aspects of process, but they would not specify precise details of how the work must be done, focusing attention instead on the end result. Clinical trial protocols, on the other hand, are of course concerned

102 Board of Appeals Decision, supra note 99, at 3.

103 Id. Note, however, that this case might have reasonably been decided as an example of joint employment.

104 Id. at 4.

$105 \mathrm{Id}$.

$106 / d$.

107 Id. at $4-5$.

108 Id. at 5. 
with the end result - the data - but are also enormously detailed with regard to schedules, procedures, and other restrictions, all features strongly indicative of an employer's type of control. Ultimately, the Board tried to draw a distinction between managing the integrity of the work (customer/contractor) and controlling its performance (employer/employee). ${ }^{109}$ However, the two are really one and the same in the clinical trials context.

In contrast to the Pharmakinetics decision, consider Edward Lowe Industries, Inc. v. Missouri Division of Employment Security, ${ }^{110}$ which reached a different conclusion on a quasi-subject's employment status for purposes of unemployment benefits. Lowe engaged the services of paid consumer panelists, including the claimant Zeta Simms, to conduct studies evaluating the odor of different cat litter formulations. ${ }^{111}$ The court considered the factors set forth by the IRS to flesh out the common law control test, and determined that on the totality of the circumstances, Simms was in fact an employee. ${ }^{112}$ However, the state unemployment law explicitly stated that 'the term 'employment' shall not include ... [s]ervices performed as a volunteer research subject who is paid on a per study basis for scientific, medical or drug related testing . . ." ${ }^{\prime 13}$ This particular statutory carve out of certain types of research subjects as nonemployees is an interesting indication of policy choice regarding which individuals ought to receive unemployment protection, but in this case, the court concluded that Simms' services did not fall within the exclusion on the grounds that the litter tests were clearly not medical or drug related, nor were they particularly scientific. ${ }^{114}$

Notably, the I.R.S. has applied its factors directly to human subjects as well, reaching the same conclusion on employment status as the court in Lowe. ${ }^{115}$ Other legal decision makers have also determined that subjects can be employees. For example, when Qualia Clinical Services declared bankruptcy, research subjects who had not been paid as promised filed claims under a priority wage provision of the Bankruptcy Code. In response to Qualia's challenge, the court held that entitlement to priority wage claims could extend even to individuals who are not employees depending on whether "something more than a 'mere contractual relationship' existed between the parties, as well as on the

109 Id. at 3.

110865 S.W.2d 855, 856 (Mo. Ct. App. 1993).

$111 \mathrm{ld}$. at $858-59$.

$112 \mathrm{Id}$. at $860-63$.

113 Id. at 863 (quoting Mo. ANN. STAT. $\S 288.034(12)(17)$ (West 1993) (current version at

$\S 288.034(12)(18)$ (West 2013)). Other states have nearly identical provisions. See, e.g., MD. Code ANN., Lab. \& EMPL. § 8-222 (West 1995); Neb. Rev. STaT. § 48-604(6)(s) (2011).

114865 S.W.2d at 863.

115 I.R.S. Priv. Ltr. Rul. 92-34-024 (Aug. 21, 1992) (determining that a paid subject participating in nutritional studies while living at a research center was an employee for purposes of tax withholding requirements). 
amount of control exercised over the claimants by the debtor."116 Because subjects had signed consent forms that were lengthy and detailed, the study protocols required rigid control, studies were conducted at Qualia's site, and the subjects were overseen by Qualia staff, the court determined that the "extent of Qualia's control over the claimants' performance in the studies effectively rendered them 'employees." "117 Qualia's role as a CRO seems to have played no part in the analysis.

Research subjects have also claimed employee status in the context of sexual harassment and minimum wage/overtime claims, although it is unclear whether they would have been successful because their cases settled out of court. ${ }^{118}$ Further, the Comptroller General has weighed in on this question, at least tangentially. In 1966, the Army sought to use civilians as human subjects in its experiments, secured under contracts on a fee basis. ${ }^{119}$ However, a government rule allowed such contracts only if the service would be performed without detailed control over the method by which the desired result would be accomplished. ${ }^{120}$ The Army explained that this condition was satisfied because it was "not interested so much in what the subject produces through his efforts, as in measuring and examining the subject's reactions to a set of conditions induced by the government. The government exercises no control over the subject's reactions in the sense of directing the subject how to react, and in fact the experimentation is valid only if his reactions are purely independent and objective." 121 The Comptroller was convinced that the situation did not "clearly fall within the rules for establishing an employee-employer relationship," "122 and saw no objection to treating the subjects as independent contractors without entitlement to leave, retirement, salary, tenure, etc. ${ }^{123}$

116 In re Qualia Clinical Servs., Inc., No. BK09-80629-TJM, 2009 WL 2513820, at 1 (Bankr. D. Neb. Aug. 11, 2009).

$117 \mathrm{Id}$. at 2.

118 Email from Scott Magaw, attorney for the plaintiffs (Feb. 12, 2012)(on file with author). The cases in question were Krah v. Univ. of Pitt., No. 2:97-cv-00834-DEZ (W.D. Pa. 1997), and Cortazzo v. Univ. of Pitt., No. 2:97-cv-00832-DEZ (W.D. Pa. 1997). See also Hank Grezlak, Research Participants Sue for Sexual Harassment, PEnN. L. WKLY., May 5, 1997; Doc Watch: Lady Lab Rats Sue Researcher, 4 GUINEA PIG ZERO 27 (article on file with author).

119 To the Sec'y of the Army, 45 Comp. Gen. 649, 649 (1966).

120 Id. at 650.

$121 \mathrm{Id}$. at 649.

122 Id. at 650 .

123 Id. at 650-51; see also SeC'y of the Air Force, Protection of Human Subjects in BIOMEdical ANd Behavioral ResearCh, Air ForCe InStruction No. 40-402 (May 5, 2005) (noting that private individuals participating as research subjects may enter into an independent contractor relationship with the Air Force). 
Beyond this handful of scattered examples, however, which present arguments and outcomes on both sides of the line, there is virtually no discussion of subjects' employment status in the legal literature. ${ }^{124}$

\section{Analysis}

The cases considering the employment status of human research subjects present a very small $n$, which is further limited by the fact that none of the cases seems to have involved unpaid research participation, therapeutic research, or patient-subjects, nor does any address issues likely to be of importance to subjects such as workers' compensation. Nonetheless, it is possible to draw a few broad conclusions.

First, despite the unique (or at least unusual) nature of the workers in question, all of the cases involved rigid application of the relevant law, without real consideration of statutory purpose, whether the subjects actually needed the protection they sought, fairness, or possible consequences. This sort of strict, formalist approach is the norm in worklaw, ${ }^{125}$ but stands in stark contrast to the policy focus of the bioethicists described above.

Second, these examples indicate that at least some types of human subjects are likely to have little difficulty with the preliminary hurdles of establishing their employee status, namely the performance of work and existence of an economic relationship. Indeed, with the exception of Pharmakinetics' point regarding the subject's body doing the work, none of the decision makers in these cases stumbled over these questions, instead simply assuming the subjects were engaged in market work and focusing exclusively on distinctions between employees and independent contractors. This is notable considering that the prevailing approach in bioethics and research compliance is to treat human subjects as though they are not engaged in work at all.

Finally, these cases suggest that legal avenues of subject protection beyond the current HSR regulations may have been under-pursued to date. That is to say, contrary to Lemmens and Elliott's point that human subjects are not considered employees, at least some legal decision makers have been willing to recognize them as such. Thus, it seems plausible that certain types of subjects seeking additional protections could conceivably achieve them even under existing law, depending on the language of the statute in question, any specific exemptions or

124 For two examples of pieces that very briefly consider whether the exclusion of women from research participation could constitute illegal employment discrimination, see R. Alta Charo, Protecting Us to Death: Women, Pregnancy, and Clinical Research Trials, 38 ST. LoUIS U. L.J. 135, 156 (1993); Vanessa Merton, The Exclusion of Pregnant, Pregnable, and Once-Pregnable People (a.k.a. Women) from Biomedical Research, 3 TEX. J. WOMEN \& L. 307, 358 n.193, 369 (1994).

125 See Guy Davidov, The Reports of My Death Are Greatly Exaggerated: "Employee" as a Viable (Though Overly-Used) Legal Concept 13-15 (May 2005) (unpublished manuscript), available at $\mathrm{http}: / /$ papers.ssrn.com/sol3/papers.cfm?abstract_id=783484. 
inclusions, and interpretation of each element in the relevant test of employment, as well as the particular details of how the research is carried out.

There is room for disagreement, but the strongest case for employee status seems to exist for paid subjects in nontherapeutic research who are motivated by money, ideally in the absence of a potentially complicating CRO. Those engaged in therapeutic research may have more difficulty establishing the market nature of their work, although this would not necessarily be insurmountable. And the weakest case exists for those who expect to receive nothing in return for their participation in research, since they are clearly volunteers under the law. For reasons that will be explored in the next Part, however, this sort of purely doctrinal approach leaves much to be desired.

\section{Clarifying THE ANALOGY AND ITS SCOPE}

Legal analysis indicates that the "human research worker" analogy might be closer to reality for some subjects, namely those likely to fit the bill as employees. However, this does not necessarily mean that direct application of existing worklaw is the best approach. Nor does it mean that the analogy fails for other types of subjects, or that they should not also be granted additional protections based on those available to workers. Rather than trying to map different types of subjects directly onto the legal standards for employees, independent contractors, and volunteers, it is preferable to think carefully about precisely which protections to incorporate into the HSR regulations, and how they should be refined for that context

\section{A. Why Not Apply Worklaw Directly to Subjects?}

A number of features of worklaw suggest that it is best used only as a model for HSR, rather than a perfect fit. Most critically, many have suggested that existing laws and interpretations are ill-suited to the modern work environment and if they are in need of modification on their home turf, there is compelling reason to worry about their application to HSR.

Part of the problem is anachronistic in the sense that the employee/independent contractor distinction that is now used to allocate responsibility for a variety of worker benefits and protections was originally developed from the master/servant doctrine of agency law for an entirely different purpose: allocating responsibility for a worker's tortious conduct. As often happens when applying rules from one situation to another, marginal cases can become difficult to handle. Moreover, as Katherine Stone explains,

[t]he legal rules governing collective bargaining and individual employment rights, as well as the provision of social welfare benefits all assumed the existence of a stable, on-going relationship between an individual and a firm. Now, as firms are 
breaking apart, downsizing, rearranging their functions, and dispersing their facilities, they no longer offer the kind of stable long-term relationship upon which our legal rules depend. ${ }^{126}$

Importantly, these concerns are rooted in features of changing working relationships that are inherent in HSR, such as temporary engagement and work for several different parties. In fact, one feature of the modern workplace that has been cited as a challenge to existing legal frameworks - outsourcing ${ }^{127}$ - has an obvious corollary in the conduct of medical research: CROs. And just as traditional workers can problematically be left unprotected as employerless employees, when the components of research are disaggregated across a number of parties in a variety of combinations, the question of who is controlling the subject becomes substantially more complicated.

Those critical of the current state of worklaw do not necessarily take issue with the fact that not all workers are covered. ${ }^{128}$ But the problem for many commentators is that the lines drawn can result in workers who seem to need protection being left without it. ${ }^{129}$ As a result, some have advocated for completely discarding the labeling distinctions between different types of workers, ${ }^{130}$ and instead simply examining whether a particular worker needs protection. ${ }^{131}$ Others have suggested experimenting with legal approaches that do not rely so heavily on employer-employee relationships as the source of worker protection; ${ }^{132}$ recognizing new intermediate labels, such as the "dependent contractor" and "uncontrolled employee"; 133 simply changing the basic definitions of employment to better encompass those workers sharing the characteristics that justify protection; ${ }^{134}$ and paying closer attention to whether entitlements that have been tied to the existence of an employment relationship really ought to be. ${ }^{135}$

The point here is not to fully engage with the criticisms of current legal approaches, but rather to note their existence and plausibility, which suggest serious concerns about the protections available to workers in general. If we

126 Stone, supra note 89 , at 254 .

$127 \mathrm{Id}$. at 253-56; Zatz, supra note 85, at 860-61; Zatz, supra note 81, at 43.

128 Davidov, supra note 125 , at 2.

129 Befort, supra note 94 , at 168 ; Carlson, supra note 81 , at 367 ; Stone, supra note 89 , at 256 270, 279; Dau-Schmidt \& Ray, supra note 91, at 117, 120.

130 But see Davidov, supra note 125 (arguing against this approach).

131 Carlson, supra note 81, at 301; Marc Linder, Dependent and Independent Contractors in Recent U.S. Labor Law: An Ambiguous Dichotomy Rooted in Simulated Statutory Purposelessness, 21 COMP. LAB. L. \& POL'Y J. 187 (1999); Stone, supra note 89, at 284.

132 Zatz, supra note 81 , at $32,57$.

133 Befort, supra note 94, at 172-74; Guy Davidov, Who is a Worker?, 34 INDUS. L.J. 57, 6162 (2005); see also Linder, supra note 131; Stone, supra note 89, at 279.

134 Zatz, supra note 81, at 51; Davidov, supra note 125, at 9, 11.

135 Alain SUPIOT, BEyond EMPloyment: Changes IN WORK AND tHE FUTURE OF LABOUR LAW IN EUROPE (2001); Davidov, supra note 125, at 3-4. 
really believe that human subjects should receive some worker-type protections, applying existing worklaw might paradoxically fail, or at least not reach all the right subjects.

\section{B. Shared Concerns of Subjects and Protected Workers}

Because the prevailing legal tests for distinguishing between different types of workers fail to generate results that correspond reliably and precisely to those who really ought to be protected - and would likely do the same for subjects given critical questions regarding who is in control and the temporary nature of research relationships - it is necessary to look beyond these tests in both contexts. But if we acknowledge that "there are some workers ('employees') . . that are in need of protection, while at the same time there are others who are capable of protecting themselves in a market environment [and] ... in the case of employees there is a corresponding employer who can and should take responsibility for their well-being,"136 it is insufficient to simply argue, as the bioethicists have, that research subjects are like workers and should be treated as such. Instead, it is necessary to demonstrate that they are more like those workers who should be protected than like those who will do fine on their own.

Leaving articulation of the perfect dividing line between protected and unprotected workers to the worklaw scholars, it seems that subjects often share not only the basic features of workers in general - at least some are engaged in commercial transactions, are paid to provide a service, and view what they do as a job - but also the very same features of workers who are unable to protect themselves and therefore deemed to need legal intervention. For example, they have divergent interests from those in positions of control, highly unequal bargaining power, strong potential for exploitation, democratic deficits, dependence, and limited alternatives. Moreover, there exists a party that can reasonably be expected to take responsibility for subjects' well-being: research sponsors. Even if sponsors are not necessarily seeking to profit from the research, and even though the burdens placed on subjects may be justifiable in light of the ends pursued, there is nothing unfair about expecting sponsors to protect the subjects used to achieve the sponsor's goal - or at least nothing less fair than expecting employers to protect their employees even when the work done has some socially valuable purpose and benefits that accrue to others.

\section{Divergent Interests}

Both workers and subjects have interests that often diverge from the interests of those in control, although this is not to say that there is no overlap. Employees and employers may share the goal of profitability, and subjects and researchers may share the mutual goal of safety. However, managers will generally extend

136 Davidov, supra note 125, at 13; see also Carlson, supra note 81, at 356. 
only those benefits necessary to attract and retain an acceptable workforce, which is precisely why the law must sometimes intervene.

Similarly, subjects and researchers or sponsors may not necessarily be overt antagonists, but they are not always on the same side of the line. For example, more amenities offered at a Phase I research facility, higher payment to subjects, more safety tests, and the like will all lead to a more expensive trial, leaving less profit for the drug company or CRO - or perhaps of greater concern, less money available for other research. Other examples abound. Including greater detail in a consent form might help shield an institution from lawsuits or liability, ${ }^{137}$ but make it more difficult for the average subject to understand. ${ }^{138}$ Sponsors have little incentive to investigate or track latent effects of trial participation, although that may be important to subjects' long-term health. And even the most upstanding researcher is (or should be) focused on the population-level benefits of increased scientific knowledge; ${ }^{139}$ in order to obtain that knowledge, subjects are inherently asked to do things that may run against their own physical interests, such as undergo tests needed only to generate data rather than to improve their care. Thus, like employees and employers, subjects and those doing the research are in many cases after different things. This is true regardless of whether the subjects are healthy or patients, paid or unpaid, or in therapeutic or nontherapeutic studies.

\section{Bargaining Power, Collective Action, and Exploitation}

In some cases, workers and subjects may also share the plight of poor bargaining power and collective action problems. As a matter of simple supply and demand, when there is a surplus of workers willing to do a job, competition between them can create a race to the bottom. Addressing this problem is another reason worklaw often intervenes in the market. ${ }^{140}$

137 See Michelle M. Mello, David M. Studdert \& Troyen A. Brennan, The Rise of Litigation in Human Subjects Research, 139 ANNALS INTERNAL MED. 40 (2003).

138 See Nancy E. Kass et al., Length and Complexity of US and International HIV Consent Forms from Federal HIV Network Trials, 26 J. GEN. INTERNAL MED. 1324 (2011) (demonstrating consent forms to be long and in excess of recommendations for how much information can be readily processed). But see Leanne Stunkel et al., Comprehension and Informed Consent: Assessing the Effect of a Short Consent Form, IRB: ETHICS \& Hum. RES., July-Aug. 2010, at 1 (finding that comprehension was generally poor and that "neither comprehension of study information nor satisfaction with the consent process was affected by either the length or the complexity of the consent form").

139 Franklin G. Miller \& Howard Brody, A Critique of Clinical Equipoise: Therapeutic Misconception in the Ethics of Clinical Trials, 33 HASTINGS CENTER REP. 19, 21 (2003).

140 Davidov, supra note 125, at 5 ("It is often said that the basic characteristic of an employment relationship - which is also the background reason for all protective labour and employment regulations - is the inequality of bargaining power between the individual employer and the individual employee."). However, Davidov contends that inequality of bargaining power is not necessarily helpful in determining which class of workers should be entitled to "employee" protections. Id. at 8 . 
Similarly, in the research context, there is often competition to get into studies, either for therapeutic or financial reasons. ${ }^{141}$ When subjects are replaceable, and particularly when their alternatives are limited, they may be unwilling to risk exclusion in order to negotiate for better terms, individually or collectively. ${ }^{142}$ Once a study has begun, subjects are in a better position considering the sunken investment in their data, ${ }^{143}$ but even then, loss of a single subject is a relatively surmountable obstacle for those conducting the research. The real concern would be losing all the subjects, and thus all the data, and having to start from scratch. However, that requires collective action, which may be difficult to muster.

The ultimate concern raised by unequal bargaining power is that subjects and workers may find themselves in circumstances of mutually advantageous consensual exploitation. In other words, they will benefit enough to make participation worth their while, but it will nonetheless be unfair if they deserve more given the burdens they are undertaking or the value of their work. ${ }^{144}$ The baseline entitlements and protections of worklaw help to address the possibility of such exploitation for workers, but many important entitlements are lacking for HSR.

\section{Democratic Deficits, Dependency, and the Need for Protection}

Finally, research subjects may face the two fundamental problems that worklaw scholar Guy Davidov identifies as justifying the extension of worker protections: "democratic deficits" and economic dependency. ${ }^{145}$ He defines democratic deficits to mean subordination to or control by another, and economic dependency in terms of one's ability to spread economic risks among a number of different relationships. ${ }^{146}$ Thus, dependency is determined by the exclusivity of the arrangement, the proportion of income derived from a particular hiring party, and the duration of the engagement. ${ }^{147}$

It seems clear that subjects often meet the subordination criterion, but dependency may be more difficult, particularly given Davidov's narrow understanding of the term. First, some subjects may not be economically dependent on research participation at all; they may not even be paid. But they may nonetheless be dependent on a trial for other benefits, such as access to

141 Ondrusek, supra note 27, at 85; Abadie, supra note 32.

142 Elliott \& Abadie, supra note 45, at 2317; Lemmens \& Elliott, supra note 43, at 52; VanderWalde, supra note 47, at 26-27; Ondrusek, supra note 27, at 121.

143 ABADIE, supra note 27, at 57-58.

144 Elliott \& Abadie, supra note 45, at 2317; Alan Wertheimer, Exploitation in Clinical Research, in Exploitation and Developing Countries: The Ethics of Clinical Research 63104 (Jennifer S. Hawkins \& Ezekiel J. Emanuel eds., 2008).

145 Davidov, supra note 133, at 63.

$146 \mathrm{Id}$. at 61-63.

$147 \mathrm{Id}$. at $67-68$. 
certain types of medical interventions unavailable elsewhere. Second, paid subjects may not be dependent on any particular trial, but rather on participation in trials in general. Similarly, a worker may have several jobs and thus be better able to withstand the loss of any one of them, while being relatively powerless in all of them because her alternatives are no better and may be worse. This creates a certain type of dependency that is admittedly broader than that articulated by Davidov, but nonetheless seems relevant. ${ }^{148}$

In a perfectly competitive market, there are enough other workers, enough other jobs, enough information, and few enough barriers that the parties will reach an ideal agreement; there is no need for legal intervention. Of course, this is often not the case, ${ }^{149}$ and Davidov acknowledges that the presence or absence of asymmetric vulnerability is an important difference when it comes to allocating legal protection between different types of workers. ${ }^{150}$ However, he maintains that a focus on unequal bargaining power is problematic for determining the proper application of worklaw protections because it is an empirical question and, more importantly, because some degree of inequality almost always exists in any market. Thus, Davidov proposes the dependency criterion as an alternative that may be more readily discernable, ${ }^{151}$ while still noting a link between the concepts: "dependency points to inequality of bargaining power; to the ineffectiveness of both voice and exit as means to protect one's self." ${ }^{\prime 52}$ And research subjects may have problems with both. Ultimately, a feature they often share with other workers who are and should be granted worklaw protections is lack of access to better alternatives.

\section{Weaker Analogy, Same Protections}

Thus, many subjects are like those workers to whom the law does and/or ought to extend protection, but this is not true across the board. Should this mean that only some subjects ought to be granted analogous new rights? Not necessarily.

First, consider subjects motivated purely by altruism, who resemble volunteer workers to whom worklaw protections usually do not extend. ${ }^{153}$ Without the pull of either therapeutic or financial need, these subjects have adequate bargaining power to protect their own interests; if they do not like the terms offered by a study, they can easily walk or hold out for better. Thus, it would be appropriate to refrain from extending worker protections to altruistic subjects, not because they do not deserve them, but because they can achieve these terms on their own.

148 Stone, supra note 89 , at 284 .

149 Davidov, supra note 125 , at 6.

$150 \mathrm{Id}$. at 8.

$151 \mathrm{Id}$.

152 Davidov, supra note 133, at 67.

153 Rubinstein, supra note 86. 
But how could we practically segregate these subjects from others to whom worker protections should be extended? A rule excluding unpaid subjects would not suffice, although it would mirror the legal rule applicable to volunteers, since subjects might still be motivated by therapeutic benefits and therefore less able to bargain effectively on their own behalf. ${ }^{154}$ A rule excluding unpaid subjects in nontherapeutic research also would not work to tease out the pure altruists because subjects might nonetheless be motivated by therapeutic benefits in light of the therapeutic misconception, ${ }^{155}$ or perhaps strong feelings of obligation to their doctors, treating institution, or others with their same ailment. Perhaps the best rule would be to exclude unpaid, healthy subjects in nontherapeutic research, although even they may be motivated by something other than altruism, such as free medical care or other nonmonetary benefits. Moreover, altruistic subjects may be paid, they are just not (primarily) motivated by that fact. Ultimately, altruistic subjects do not need worker protections, but it is likely better to be over-inclusive here, since extending worker protections to altruists would simply grant them at least what they would demand in order to be willing to participate in the first instance, whereas excluding them could potentially sweep up some subjects who really are in need. ${ }^{156}$

On the other hand, some subjects who would benefit from the extension of worker protections and could not effectively bargain for them actually seem different from protected workers in important ways. For example, unpaid subjects lack a defining characteristic of the protected worker: payment for labor. And subjects in therapeutic research may be paid, but also differ from protected workers in that the benefits they predominantly anticipate are completely outside the commercial context. Thus, it is not quite right to suggest that these subjects ought to be treated just like protected workers because they are just like protected workers. They are not. Nevertheless, payment to workers is not itself what renders them in need of protection; instead, it is dependence on that payment, which in turn reduces their bargaining power. Subjects - paid or not, seeking noncommercial benefits or not - can be similarly dependent, with similar outcomes.

Clearly, the law does not intervene every time there is a disparity in bargaining power, but it often does. Moreover, it specifically protects weak workers, albeit imprecisely, from a number of problems that also threaten weak subjects. And perhaps most importantly, the government is far from hands off in the research context. For decades, subjects have been viewed as in need of stringent regulatory protection, and intrusion in the relationship between

154 Note that a similar problem arises when volunteers actually need the volunteer opportunity for some other purpose, such as college credit for an internship, which impedes on their ability to bargain and exit. See, e.g., id. at 151.

155 Paul S. Appelbaum \& Charles W. Lidz, The Therapeutic Misconception, in THE OXFORD TEXTBOOK OF CliniCAL RESEARCH ETHICS, supra note 18, at 633-44.

156 See Davidov, supra note 125, at 11. 
researcher and subject is commonplace, as exemplified by the regulatory requirements for IRB review and approval, specific standards for acceptable consent, control over subject recruitment and compensation, and the like. Against this background, it seems that subjects should be at least as well protected as workers when they face similar problems, even when the analogy is imperfect.

\section{LEVELING SUBJECTS UP TO WORKERS}

When groups that are the same in relevant respects face uneven treatment, consistency demands that the unevenness be remedied, which can occur either by leveling up or leveling down. For example, in those cases where workers are more protected than subjects - our focus here - the difference could be eliminated by granting subjects those same protections or stripping those protections from workers. However, considering that workers really seem to need the protections they are granted, the latter option of leveling down would be unwarranted and inappropriate. Moreover, considering that we have far more experience with regulation of the workplace than with regulation of human subjects research, and because many more people are traditional workers than are research subjects, existing worklaw protections are likely to be a better reflection of social norms and agreement than the absence of those protections in the research setting. ${ }^{157}$ Thus, the remaining options are: (1) to level subjects up for parity with the legal status quo applicable to workers, while acknowledging that workers (and therefore subjects) should sometimes be even more protected than they currently are, or (2) to identify some relevant distinction justifying a particular difference in treatment. What follows will consider which of these approaches is warranted for some of the most pressing and obvious disparities between the two groups.

\section{A. Payment}

One of the most highlighted differences between research participation and employment - indeed, the one that got Lemmens and Elliott going - is the disparity in how payment is regulated in either case. The HSR regulations permit subject payment, but include no minimum wage requirement. They also impose no maximum, but the general regulatory requirement to protect consenting subjects from undue inducement in practice acts as a variable payment ceiling. ${ }^{158}$ Moreover, although technically silent on the matter of whether payment to

157 Sachs, supra note 7 , at 75 .

15845 C.F.R. § 46.116 (2013); 21 C.F.R. $\$ 50.20$ (2013); OHRP, Informed Consent, supra note 42; OHRP, Institutional Review Board Guidebook: Chapter III, HHS § G (1993), http://www.hhs.gov/ohrp/archive/irb/irb_chapter3.htm [hereinafter OHRP, IRB Guidebook] (section on "incentives for participation"); see also Emily A. Largent et al., Money, Coercion, and Undue Inducement: Attitudes about Payments to Research Participants, IRB: ETHICS \& HUM. RES., Jan.-Feb. 2012, at 1 (finding that IRB members are very concerned that subject payments will lead to undue inducement, which may result in limiting the payments offered). 
subjects may be based on risk, the regulations' direction to avoid undue inducement is often taken to mean that risk-based payment is impermissible. ${ }^{159}$ Federal regulators have recently made an effort to clarify that remuneration to subjects may indeed include compensation for risks, and that compensation may be treated as an acceptable motive for subjects agreeing to participate in research. However, IRBs are nonetheless cautioned that such remuneration should not be treated as offsetting research risks in the analysis that boards themselves are required to undertake before approving research proposals. And still, IRBs are warned to ensure that "payments are not so high that they create an 'undue influence' or offer undue inducement that could compromise a prospective subject's examination and evaluation of the risks or affect the voluntariness of his or her choices." ${ }^{160}$ Ultimately, the concern is that the offer of high payment may be so irresistible to subjects that it will lead them to exercise poor judgment in accepting unnecessary, unreasonable, and excessive risks of serious harm, i.e., risks that a reasonable person would not assume. ${ }^{161}$

Whether undue inducement ought to be a relevant consideration in the research context is a matter of significant debate, ${ }^{162}$ but what is clear is that fear of undue inducement plays no role whatsoever in the legal regulation of wages paid to workers. In fact, worklaw imposes no ceiling - explicit or implicit - on how much workers may be paid, although other factors may. And in theory, the market should dictate (and some laws do) ${ }^{163}$ that risky work be better compensated, a phenomenon called the compensating wage differential. ${ }^{164}$ Further, even when risky jobs are held by those with few other options for less risky work that is comparably compensated, the law does not require that their payment be restricted on that basis. ${ }^{165}$ Worklaw does, however, impose a compensation floor in some cases. Workers meeting the Fair Labor Standards Act's definition of nonexempt employee are entitled to be paid the federal minimum wage of $\$ 7.25$ per hour (since 2009), and at least one and a half times

159 See Sachs, supra note 7, at 70.

160 OHRP, Informed Consent, supra note 42.

161 Ezekiel J. Emanuel, Undue Inducement: Nonsense on Stilts?, 5 Aм. J. BIOETHICs 9 (2005); OHRP, IRB Guidebook supra note 158; see also Dickert \& Grady, supra note 29, at 390 (providing a somewhat different definition of undue inducement as characterized by a choice to engage in an activity even though a subject finds it objectionable in some significant way).

162 See, e.g., Emanuel, supra note 161; Ruth Macklin, 'Due' and 'Undue' Inducements: On Paying Money to Research Subjects, IRB: ETHICS \& HUM. RES., May 1981, at 1; McNeill, supra note 7, at 393; Savulescu, supra note 46.

163 See, e.g., 5 C.F.R. pt. 550, subpart I (2013) ("Pay for Duty Involving Physical Hardship or Hazard").

164 But see Kevin Purse, Work-Related Fatality Risks and Neoclassical Compensating Wage Differentials, 28 CAMBRIDGE J. ECON. 597 (2004).

165 See Miller \& Wertheimer, supra note 22, at 91 ("Note that we do not say that people are coerced into taking jobs because they would otherwise be poor or unemployed."). 
the regular rate of pay for overtime worked beyond 40 hours per week; ${ }^{166}$ state and local minimum wages may be even higher.

Then again, there are circumstances in which employment law permits workers to go without payment, provided that they are either true volunteers altruistically contributing to public welfare or are otherwise receiving adequate nonmonetary compensation in the form of training or reputational benefit. ${ }^{167}$ Unpaid research participation may also be acceptable under similar circumstances, ${ }^{168}$ such as non-profit research conducted for the common good or other types of research participation that offer therapeutic promise directly to subjects adequate to compensate for their contribution. There are, of course, no such prerequisites for unpaid research participation under the current regulatory scheme. But even if we leave aside those circumstances in which subjects are not paid but should be, the question remains: when a decision has been made to offer payment for research participation, ${ }^{169}$ is there any reason subjects should not be entitled to the same payment protections and liberties as paid workers?

One possibility is simple paternalism; we do not want subjects to exchange their health for money, so we seek to discourage them from doing so to the extent compatible with achieving sufficient enrollment. But even if one accepts paternalistic justifications for regulation as legitimate, they fail to explain the difference in treatment between subjects and other workers who also face various physical risks for pay. There may also be some initial concern regarding topics like commodification of the research subject, crowding out altruists, or transformation of what should be a gift relationship into a commercial

166 Wage \& Hour Div., Compliance Assistance - Wages and Fair Labor Standards Act (FLSA), U.S. DEP'T LAB., http://www.dol.gov/whd/flsa/ (last visited Nov. 22, 2013).

167 See, e.g., Office of the Assistant Sec'y for Policy, Fair Labor Standards Act Advisor: Volunteers, U.S. DEP'T LAB., http://www.dol.gov/elaws/esa/flsa/docs/volunteers.asp (last visited Nov. 22, 2013); Wage \& Hour Div., Fact Sheet \#71: Internship Programs Under the Fair Labor $\begin{array}{lllll}\text { Standards Act U.S. DEP'T 2010), } & \end{array}$ http://www.dol.gov/whd/regs/compliance/whdfs71.pdf.

168 Some argue that unpaid research is one way to avoid subject exploitation. See Trisha Phillips, Exploitation in Payments to Research Subjects, 25 BıETHICs 209, 217-218 (2011) ("Avoiding exploitation does not require that researchers pay a fair wage; it merely requires that they do not pay less than a fair wage.").

169 On the general question of whether subject payment is itself ethically permissible, there is a tremendous body of literature considering aspects like the impact of payment on risk assessment and consent, the tension between protecting against undue inducement and avoiding exploitation, and various mechanisms of setting payment rates to avoid these problems. See ABADIE, supra note 27, at 6-7, 65-84; Dickert \& Grady, supra note 29, at 386-96; Emanuel, supra note 161; Scott D. Halpern, Financial Incentives for Research Participation: Empirical Questions, Available Answers and the Burden of Further Proof, 342 AM. J. MED. SCI. 290 (2011); McNeill, supra note 7; Open Peer Commentaries, Money for Research Participation: Does It Jeopardize Informed Consent? 1 AM. J. BIOETHICS 45, 45-68 (2001) (multiple authors); Phillips, supra note 168; VanderWalde \& Kurzban, supra note 26; Martin Wilkinson \& Andrew Moore, Inducement in Research, 11 BIOETHICs 373 (1997); Ondrusek, supra note 27, at 18-34, 188-201. 
transaction. ${ }^{170}$ However, so long as the regulations permit subjects to be paid beyond simple reimbursement of their expenses, it seems the ship has sailed on these concerns, and the focus should instead be on ensuring fair payment amounts. Moreover, it really should be no more worrisome to commodify a person's labor as a research subject than to commodify a person's labor in other contexts, which happens all the time. Crowding out seems also to be a red herring given that at least one of the reasons payment is currently offered is that altruistic research participation does not suffice to meet demand, ${ }^{171}$ not to mention the fact that altruistic subjects are always free to reject payment, if they so choose. And there seems to be no discernible reason that research participation ought to be treated as a gift when people prefer to be paid. Finally, and most importantly, it is essential to recognize that none of these concerns actually drive the regulation of payment to subjects, which instead is rooted exclusively in fears of undue inducement. And so the question stands: why should paid subjects and paid workers not be treated the same with regard to that payment?

\section{Payment Ceiling}

Breaking down the different aspects of payment, note that the concept of a payment ceiling might be viewed as unique among the disparities between the HSR and worklaw regimes considered herein. Elsewhere, we focus on circumstances in which subjects are decidedly less protected than workers. However, the absence of a payment ceiling in the context of most traditional work might be characterized as a freedom rather than a protection, whereas the presence of a ceiling for research participation is generally billed explicitly as a subject protection. Thus, in this context, subjects might appear to be more protected than workers at present, throwing a wrench into the rationale for maintaining that it is the subject side of the analogy that should be open to regulatory amendment and enhanced protections; eliminating the payment ceiling could be viewed as leveling subjects down. On the other hand, there is also an important sense in which restricting subject payment is not protective at all: payment restrictions open subjects up to the exploitative possibility of being paid too little, in which case it is the absence of a payment ceiling that is more protective, as in the work setting. Given the dual nature of the payment restrictions applicable to HSR - protective against undue inducement but permissive of exploitation - it is necessary to step back and confirm that worklaw provides the appropriate fixed standard when it comes to resolving payment

170 See, e.g., Tod Chambers, Participation as Commodity, Participation as Gift, 1 AM. J. BIOETHICS 48 (2001). For a discussion of these arguments and why they fail to prove that payment to subjects at any level is inherently problematic, see Dickert \& Grady, supra note 29 , at 391.

171 Note that the fact that research subjects can be paid places HSR in stark contrast to organ donation, where crowding out is an oft-cited argument against initiation of an organ market, albeit one with scant empirical evidence to support it. See Julia D. Mahoney, Altruism, Markets, and Organ Procurement, 72 LAW \& CONTEMP. ProBS. 17, 24-26 (2009). 
inconsistencies between subjects and workers. In other words, should we be considering a payment ceiling for workers too?

Note that a maximum wage for work is not completely unheard of. In fact, maximum wage laws existed in colonial America, ${ }^{172}$ and were also passed by some state legislatures in the South after emancipation for reasons that were decidedly anti-worker. ${ }^{173}$ More recently, some have suggested a cap on executive compensation to help avoid adverse effects on economic conditions and financial stability. ${ }^{174}$ Similarly, many professional sports leagues have adopted private pay scales and salary caps that limit how much any player may receive in order to keep more teams in the competitive range and preserve entertainment value. ${ }^{175}$ And government employees (and grant recipients) are also subject to maximum pay rates to ensure judicious use of citizens' tax dollars. ${ }^{176}$

In none of these examples, however, is payment limited out of fear that workers will suffer from undue inducement. In fact, when it comes to risky work, many would suggest that workers deserve to be paid substantially more, not less. ${ }^{177}$ Higher pay would likely also attract a broader swath of the population to risky work, potentially allowing risks to be more evenly distributed rather than concentrating them on the very worst off. Thus, rather than introducing fresh concerns regarding undue inducement into the employment setting, it is more appropriate to treat freely paid risky work as the fixed comparator. The next step is to assess whether there is any reason to be more concerned when subjects accept risks because they want or need the money, and whether this heightened concern would justify retention of the payment ceiling in the research context alone.

A number of reasons have been suggested in the literature, all of which fail. For example, it cannot be that risks to subjects are greater, because the greatest risk - death - is also present in some jobs. And it cannot be that the risks to subjects are unreasonable or cannot be minimized, since this is specifically regulated by IRBs. Nor can it be that risks to subjects are more uncertain or

172 William P. Quigley, Work or Starve: Regulation of the Poor in Colonial America, 31 U.S.F. L. REV. 35, 69 (1996).

173 James Gray Pope, Contract, Race, and Freedom in the Constitutional Law of "Involuntary Servitude," 119 Y ALE L.J. 1474, 1534-1535 (2010).

174 Sarah B. Patterson, Note, Protecting Your Rights, But Not Your Paycheck: How Executive Compensation Regulation Passes Constitutional Muster, 113 W. VA. L. REV. 931 (2011); Sam Pizzigati, The Corporate Pay Gap: Do We Need a Maximum Wage?, PeRSP. ON WORK, Summer 2009, http://www.lera.uiuc.edu/pubs/perspectives/CompArticles/POW_13.1--Pizzigati.pdf.

175 See John Clayton, What New CBA Means in Football Terms, ESPN (July 25, 2011), hitt://espn.go.com/nfl/story/_id/6790759/what-new-nfl-cba-means-football-terms.

176 See, e.g., 5 C.F.R. $\$ 531.221$ (2013) ("Maximum Payable Rate Rule"); Frequently Asked Questions: NIH Salary Cap in FY2012, NAT'L INSTS. HEALTH, http://grants.nih.gov/grants/policy/fy2012_salary_cap_faqs.htm (last updated Feb. 14, 2012).

177 Some argue this is true for research as well. See, e.g., Eleri Jones \& Kathleen Liddell, Should Healthy Volunteers in Clinical Trials Be Paid According to Risk? Yes, 340 BRIT. MED. J. 130 (2010); Jerry Menikoff, Just Compensation: Paying Research Subjects Relative to the Risks They Bear, 1 AM. J. BIOETHICS 56 (2001); Ondrusek, supra note 27, at 29, 192. 
unknown. ${ }^{178}$ First, it is unclear why a range of possible risk from minor to severe should be more worrisome than a known risk concentrated at the higher end of the spectrum, which is true of some jobs. Second, just because research involves uncertainty does not necessarily mean that sensible predictions are impossible. ${ }^{179}$ Third, "it is probably false that research risks are, in general, poorly understood compared to the risks undertaken by employees and volunteers. In fact, some employees and volunteers, such as test pilots, take risks every day without knowing their extent." ${ }^{180}$ And finally, to the extent that the inherent uncertainty of research risk is not deemed to invalidate subject consent, it does not seem to exacerbate the potential for undue inducement.

Perhaps the difference is that subjects are taking risks for the benefit of others, so we should be especially concerned that those risks are undertaken voluntarily, but that rationale fails as well. Firefighters also take risks for the benefit of others, and paid subjects are often taking risks for their own financial benefit. There may be a concern about therapeutic misconception in research that is not present in the context of work, ${ }^{181}$ but if anything, payment could help make clear that research is different from clinical care. ${ }^{182}$ And for both healthy and patient-subjects, payment amount may be an important indication of risk level. ${ }^{183}$ Some worry that payment might blind subjects to potential risks, whereas workplace risks may be more obvious, but empirical evidence on this is scant, ${ }^{184}$ and if it is a legitimate concern, the appropriate solution is to improve research consent before restricting payment. ${ }^{185}$ Some also maintain that it is disrespectful to offer people money to entice them to overcome deeply held objections based on their values, desires, or fears. ${ }^{186}$ However, it happens all the time - just consider the number of law school graduates who head straight for a high-paying firm job knowing that the hours will make them unhappy or that they will pursue goals for their clients that they personally disagree with. Ultimately, none of these reasons convincingly suggest that avoidance of undue inducement is a reason to limit payment to subjects but not to workers, or for that matter, to reject

$178 \mathrm{McNeill}$, supra note 7 , at 391.

179 Timothy Wilkinson, Assessing the Case for the Regulation of Research, 10 AM. J. BIOETHICS 63, 64 (2010).

180 Sachs, supra note 7 , at 74 .

181 Id. at $74-75$.

182 Dickert \& Grady, supra note 29, at 392 (also noting that payment to patient-subjects could "depersonalize the exchange, making it easier for patients to refuse and putting them on more equal bargaining terms with investigators").

183 See Cynthia E. Cryder et al., Informative Inducement: Study Payment as a Signal of Risk, 70 Soc. SCI. \& MED. 455 (2010).

184 See Scott D. Halpern et al., Empirical Assessment of Whether Moderate Payments Are Undue or Unjust Inducements for Participation in Clinical Trials, 164 ARCHIVES INTERNAL MED. 801 (2004) (finding no evidence that commonly used payment levels represent undue inducements).

185 Dickert \& Grady, supra note 29 , at 389.

186 Id. 
risk-based payments to subjects when such payments are expected and encouraged for other work.

There are, however, a few possible concerns beyond undue inducement that have been suggested as rendering unrestricted payment particularly worrisome in the research setting. First, some subjects motivated by money may lie or withhold information in order to enroll or stay in a trial, ${ }^{187}$ and/or enroll in multiple trials, leading to both methodological and ethical concerns. For example, the validity of trial data may be jeopardized if subjects fail to disclose prior or concurrent study participation, evade exclusion criteria, violate study requirements, or fail to report side effects. These behaviors might also hurt subjects themselves. ${ }^{188}$

But does this really set research apart? Workers may lie about their qualifications too, in ways that put both themselves and their employers' output in jeopardy, and they may be enticed to do so by money. And their lies are in many cases objectively detectable; a manager can ask for training certificates, speak with previous employers, test competence, carefully oversee the work, and the like. Similarly, although US regulations do not currently address the issue of repeat or simultaneous participation, regulatory bodies, sponsors, and researchers could implement national subject registries to track participants, ${ }^{189}$ impose and enforce mandatory wash-out periods between trials, institute lifetime enrollment caps, utilize more extensive screening before enrollment, and increase use of physical testing rather than relying on qualitative subject feedback whenever possible. $^{190}$ Unless these solutions were unsuccessful, and unless empirical evidence suggests that scientific integrity and subject safety are indeed being harmed by the offer of unrestricted payment for participation, the fact that paid subjects might be more likely to lie than those who are unpaid cannot justify a limit on compensation to subjects but not for other jobs.

What about concern that without an upper limit on payment, some important research will likely be unable to compete for subjects? ${ }^{191}$ This would be regrettable, but this problem is not unique to research either. In all sorts of jobs, the public sector and non-profits must compete for workers with the private sector and profit-driven companies. They often do so in non-monetary ways, for example, by emphasizing civic duties and the importance of helping others. Even when one company's mission might be clearly more desirable (from a moral perspective) than another's, we do not limit the payment that can be offered by

187 Id. at 390; Carl L. Tishler \& Suzanne Bartholomae, Repeat Participation Among Normal Healthy Research Volunteers: Professional Guinea Pigs in Clinical Trials?, 46 PERSP. Biol. \& MED. 508, 512-13 (2003); Ondrusek, supra note 27, at 42, 90, 103, 143. Note, however, that this could be an issue for any subject motivated for reasons other than altruism.

188 ABADIE, supra note 27, at 154-55; Elliott, supra note 30; Elliott \& Abadie, supra note 45, at 2317; Tishler \& Bartholomae, supra note 187, at 511, 512, 514-15; Wilkinson \& Moore, supra note 169 , at 388 ; Ondrusek, supra note 27 , at $42,90,103,143$.

189 See Resnick \& Koski, supra note 38; Tishler \& Bartholomae, supra note 187, at 517.

190 Tishler \& Bartholomae, supra note 187 , at 513.

191 Dickert \& Grady, supra note 51, at 201; Trisha B. Phillips, A Living Wage for Research Subjects, 39 J.L. MED. \& ETHICS 243, 243 (2011). 
either. As a result, some socially valuable projects simply cannot flourish. Unless clinical research is somehow different from these other important projects, which may also aim to save lives or otherwise improve the world, competition for subjects is not a reason to limit payment for participation. Note that the same rationale applies to the concern that high payment to subjects will drive up the cost of doing research and take resources from other important projects.

Ultimately, regardless of whether there is reason for genuine concern about undue inducement of research subjects and/or other potential negative effects of unrestricted or risk-based payment, there seem to be only two possible reasons to treat research differently from other types of work in this regard, and both are somewhat hypothetical. If high payments would in fact damage scientific integrity, or if some essential research that is deemed more important than other endeavors cannot compete for subjects, then it would be possible to justify regulatory restrictions on subject payment even when such restrictions are not present for other types of work. And of course, some types of payment restriction for research participation would be completely consistent with a work regime, such as a private "salary cap" negotiated between a group of sponsors and subjects, ${ }^{192}$ or a regulatory cap for subjects in government-funded research. But these circumstances would be exceptional, whereas restricted payment is now the rule for HSR. Thus, we have our first case in which the subject-worker analogy calls for a substantial rule change. ${ }^{193}$

\section{Minimum Wage}

Removing payment restrictions for research subjects will eliminate one excuse for payments that are too low. But, focusing again on consistency and the need to treat like cases alike, should subjects also be guaranteed the minimum wage? The reasons that supported unrestricted subject payment as discussed above seem to suggest that here too the answer is yes. However, there are some relevant differences in purpose that indicate the minimum wage need not be extended to all paid subjects.

States began to introduce minimum wage laws in the early twentieth century out of concern that many workers who were unable to effectively bargain with their employers were receiving a wage below that necessary to provide an

192 A private salary cap would be permissible only if agreed upon in collaboration with subjects through a labor agreement or if Congress adopted some exemption to antitrust laws for the research context. See Labor and Collective Bargaining, AM. ANTITRUST INST., http://www.antitrustinstitute.org/content/labor-collective-bargaining (last visited Nov. 22, 2013).

193 Others have also argued that there should be no upper limit on subject payment, but not necessarily for all the same reasons articulated here and not necessarily for all subjects. See, e.g., Ackerman, supra note 28, at 1, 3; Anderson \& Weijer, Wage Earner, supra note 57, at 375 n.8; Elliott \& Abadie, supra note 45, at 2317; Lemmens \& Elliott, supra note 43, at 53; David B. Resnick, Research Participation and Financial Inducements, 1 AM. J. BIOETHICS 54, 55 (2001); Shamoo \& Resnick, supra note 34 , at W10. 
adequate standard of living. The federal minimum wage was initially stimulated by a desire to raise purchasing power and boost the economy, but the rationale eventually expanded to include poverty reduction goals as well. ${ }^{194}$ Among other things, Congress noted that "labor conditions detrimental to the maintenance of the minimum standard of living necessary for health, efficiency, and general well-being of workers" burden commerce, constitute an unfair method of competition, and lead to labor disputes. ${ }^{195}$

Importantly, these rationales for the minimum wage seem to apply only to those research subjects who participate in research instead of or to complement other work. For these subjects, the amount paid really does influence their standard of living and purchasing power. In contrast, the rationales for a minimum wage do not fit subjects who participate in research primarily for altruistic or therapeutic reasons, even though they may also be paid and even when payment might have pushed them over the tipping point in agreeing to enroll. ${ }^{196}$ The difference is really whether subjects experience payment as a bonus or as a wage. This could be operationalized, albeit somewhat imperfectly, by extending the applicable minimum wage only to paid healthy subjects participating in nontherapeutic research. Not everyone in this category may actually need to be guaranteed the minimum wage, since at least some research currently pays more and at least some subjects will select alternative opportunities when the pay offered is insufficient. However, the same is true for other work where the minimum wage is nonetheless extended because some workers do need it - if Mark Zuckerberg flipped burgers for McDonald's, he would be entitled to the same payment protections as everyone else.

That being said, there would be a few complexities associated with extending the minimum wage to research subjects. For example, some of those who argue that subjects currently get paid too little actually break down the subjects' compensation into an hourly rate and call for overtime pay even though subjects are not actively engaged in participation during the entire period of their enrollment. ${ }^{197}$ Even in a confinement study, subjects are usually free for several hours a day to pursue leisure activities of their own choosing, and in any study, each hour of time spent as an enrolled subject is not worthy of equal compensation. Thus, the question is whether subjects are closer to the security guard $^{198}$ who gets paid for an entire shift even if he does no more than read a book, or to the on-call employee who may not be entitled to the minimum wage

194 John Foley, Note, Questioning the Merits of Federal Minimum Wage Legislation, 5 GEO. J.L. \& PuB. PoL'Y 679, 681-82 (2007); David Neumark \& William Wascher, Minimum Wages and Low-Wage Workers: How Well Does Reality Match the Rhetoric?, 92 MINN. L. REV. 1296, 1298 1303 (2008).

19529 U.S.C. § 202(a) (2006).

196 This distinction resolves potential uncertainty as to how to appropriately compensate subjects monetarily when they are getting nonfinancial benefits from participation.

197 Anderson \& Weijer, Entrepreneur, supra note 57, at 68.

198 See ABADIE, supra note 27, at 2-3. 
or overtime for hours spent on call. ${ }^{199} \mathrm{~A}$ further question is whether subjects are confined for their own benefit so that they may be cared for in case of adverse events, or for the benefit of the study to ensure compliance. ${ }^{200}$

Ultimately, the standard hourly minimum wage may be a poor fit for HSR, given that subjects can be variably involved in active study visits, passive observation periods, overnight confinement, and/or tasks carried out while at home. Nonetheless, some regulatory minimum ought to exist for certain types of subjects, and compensation based on a minimum rate per procedure, per day of confinement, or per study visit may be most parsimonious. Again, for parity with protected workers, the goal is to ensure that paid healthy subjects in nontherapeutic research are paid an amount similar to what they could expect in other minimum wage jobs given the same level of commitment and exertion. Note, however, that this will not necessarily protect subjects against exploitatively low payment, ${ }^{201}$ just as traditional workers may not be protected. This is because fair payment based on contribution, time, inconvenience, risk, discomfort, and other burdens may actually be higher than the minimum wage, which takes none of these factors into account. ${ }^{202}$ In other words, the minimum wage is often too low for workers or subjects. Moreover, considering that many subjects are already getting paid amounts that make it worthwhile to participate in research instead of taking other jobs, ${ }^{203}$ it is likely that removing the payment ceiling will be the far more important change.

\section{Unemployment}

A final factor relevant to payment that ought to be briefly addressed (especially given that research subjects have in fact sought eligibility for it) is unemployment compensation. Employees are generally eligible for

199 Most courts have held that when an on-call employee is free to engage in personal activities, such as watching television or visiting with friends, the time spent on call is not compensable under FLSA, even when he has considerable restrictions placed on his geographic mobility and activities. However, some courts have found on-call time to be compensable when these restrictions are extreme and the employee is frequently called in to work. Stone, supra note 89 , at 258 . On the other hand, at least one court has held that even when the employee must remain at the work site when on call, his time is not compensable when he is free to "free to sleep, eat, watch television, watch VCR movies, play ping-pong or cards, read, listen to music ...." Rousseau v. Teledyne Movible Offshore, Inc., 805 F.2d 1245, 1248 (5th Cir. 1986).

200 See, e.g., Armour \& Co. v. Wantock, 323 U.S. 126, 132 (1944) (holding that waiting time is compensable under FLSA if it is "primarily for the benefit of the employer and his business" (quoting Tennessee Coal, Iron \& R. Co. v. Muscoda Local, 321 U.S. 590, 597-98)).

201 Phillips, supra note 168, at 210-12. There is also a sense in which subjects might be exploited by payments that are too high if that would cause undue inducement. See VanderWalde \& Kurzban, supra note 26, at 552 .

202 See Phillips, supra note 191.

203 See Jessica Latterman \& Jon F. Merz, How Much Are Subjects Paid to Participate in Research?, I AM. J. BIOETHICS 45 (2001) (finding that average subject payments exceeded the minimum wage). 
unemployment when they become involuntarily unemployed. ${ }^{204}$ However, states differ with regard to whether an employee will be considered to have quit voluntarily when he knowingly takes a temporary job that ends as planned. ${ }^{205}$ Thus, failure to extend benefits to subjects may not actually be inconsistent with the treatment of other workers, at least not in all jurisdictions, given the temporary nature of research participation. But even if we assume that temporary workers should be covered, there is good reason that research subjects should not.

One of the goals of unemployment compensation is to stabilize employment, which it achieves through a stick: an experience rating that requires employers to pay an additional tax for its former employees receiving unemployment benefits. ${ }^{206}$ This does not fit the research context, however, because the work offered in any given study will never be permanent (even if a given subject is a "professional"), leaving nothing to incentivize through the experience rating. Moreover, it does not seem fair to expect a party to subsidize unemployment when it could not have helped a subject avoid it. ${ }^{207}$ Even if subjects would benefit from such protection, there is no one but the government that could be appropriately asked to pay, and other aspects of the social safety net seem better suited to help smooth the transition for those who rely on research participation for money. ${ }^{208}$

\section{B. Care and Compensation for Injury}

Moving on from payment for participation, another key area in which the HSR regulations seem to offer less protection than worklaw has to do with what

204 StafF of H. COMm. on Ways \& MEans, 112TH CONG., 2012 Green Book: Background Material and Data on the Programs Within the Jurisdiction of the Committee on Ways AND MEANS, at ch. 4 (Comm. Print 2012), http://greenbook.waysandmeans.house.gov/2012-greenbook/chapter-4-unemployment-insurance/introduction-and-overview

(subsection on "Unemployment Insurance Introduction and Overview").

205 Sachin S. Pandya, Retrofitting Unemployment Insurance to Cover Temporary Workers, 17 YALE L. \& POL'Y REV. 907, 919-23 (1999); Stone, supra note 89, at 264-66.

206 Gillian Lester, Unemployment Insurance and Wealth Redistribution, 49 UCLA L. REV. 335, 344-45 (2001); Pandya, supra note 205, at 925.

207 A potential analogy here are the exceptions found in some state laws that permit seasonal employers to avoid certain unemployment insurance requirements and that disqualify seasonal employees from receiving benefits for unemployment outside the normal operating season. See generally Rex Williams, Seasonal Unemployment Compensation: Insurance of a Known and Certain Loss, 4 SAN JOAQUIN AGRIC. L. REv. 75 (1994).

208 Another problem is that those receiving unemployment benefits must accept "suitable" offers of work, and similar work to that lost is generally deemed suitable. Pandya, supra note 205, at 923-24. Thus, unemployed subjects might be compelled to enroll in other studies for which they are qualified or lose their entitlement to compensation, in violation of the voluntariness requirement imposed by the research regulations. 45 C.F.R. $\S 46.116(\mathrm{a})(8)(2013) ; 21$ C.F.R. $\S 50.25(\mathrm{a})(8)$ (2013). The same is true whenever someone takes a job simply because the fact that it was offered renders them ineligible for future unemployment benefits, although there may be reason to believe that voluntariness is more important in research than in other types of work. 
happens in the event of injury. On the one hand, with the exception of limited policies adopted by a handful of federal agencies, ${ }^{209}$ the regulations do not require that any special provisions be made for subjects harmed via research participation. ${ }^{210}$ On the other, injured subjects are free to pursue usual legal remedies, and the regulations preclude informed consent materials from including any exculpatory language. ${ }^{211}$ However, for all litigants, the tort system is "time-consuming, adversarial, expensive, and has a tendency to undercompensate most ... [of those injured] while over-compensating a select few."212 Unfortunately, it is even more problematic for injured research subjects, who are likely to have difficulty showing that any duty to them was breached, that the research caused their injury, ${ }^{213}$ that they did not assume the risk through informed consent, and most importantly, that their injury was anyone's fault, since even perfectly conducted research can result in harm. ${ }^{214}$ Moreover, several classes of research subjects, particularly those in federally conducted and international research, are prevented from receiving compensation altogether as a result of statutory and procedural barriers to tort litigation. ${ }^{215}$

In contrast, most employers are legally responsible under various workers' compensation statutes for guaranteeing payment of benefits to covered employees $^{216}$ who sustain injuries (including illness and death) that "arise out of"

209 See Moral Science, supra note 17, at 65-66 (and accompanying notes), 184-85 (describing limited provisions to provide free care to subjects injured in studies sponsored by entities such as the Department of Defense, Department of Veterans Affairs, NIH Clinical Center, Environmental Protection Agency, and NASA).

210 Cf. 45 C.F.R. $\$ 46.116(a)(6) ; 21$ C.F.R. \& 50.25(a)(6) (requiring that informed consent include an explanation of whether any compensation is provided in the event of injury).

21145 C.F.R. § 46.116; 21 C.F.R. § 50.20; OHRP \& FDA, Guidance on Exculpatory Language in Informed Consent, HHS (Aug. 19, 2011), http://www.fda.gov/downloads/RegulatoryInformation/Guidances/UCM271036.pdf (draft guidance).

212 Elizabeth R. Pike, Recovering from Research: A No-Fault Proposal to Compensate Injured Research Participants, 38 AM. J.L. \& MED. 7, 23 (2012). See also Wendy K. Mariner, Compensation for Research Injuries, in 2 Women AND HEALTH RESEARCH: ETHICAL AND LeGal Issues of InCluding Women IN CliniCal Studies, 113, 121 (Anna C. Mastroianni et al. eds., 1994); Resnick, supra note 31 , at 283.

213 Inst. of Med. (IOM), Responsible Research: A Systems Approach to Protecting Research Participants 193 (Daniel D. Federman et al. eds., 2002); Robert Steinbrook, Compensation for Injured Research Subjects, 354 NEW ENG. J. MED. 1871, 1872 (2006).

214 See IOM, supra note 213, at 188; Pike, supra note 211, at 23-24, 26-29; Larry D. Scott, Research-Related Injury: Problems and Solutions, 31 J.L. MED. \& ETHICS 419, 423 (2003); VanderWalde and Kurzban, supra note 26, at 546.

215 See Pike, supra note 212, at 29-38 (referring to sovereign immunity, the Federal Tort Claims Act and its discretionary function exception, the Alien Tort Statute, and forum non conveniens). This problem is solidified by the Supreme Court's decision in Kiobel v. Royal Dutch Petroleum, 133 S.Ct. 1659 (2013) (holding that the presumption against extraterritoriality constrains courts exercising their power under the Alien Tort Statute).

216 This includes the vast majority of employers and employees in traditional employeremployee relationships. There are, however, some statutory exceptions in both directions. For 
and "in the course of their employment," without regard to the fault of either party. In exchange, employers are immunized from tort suits for negligence in causing or contributing to the injury. ${ }^{217}$

Before this system was in place, injured workers were seldom compensated, for a variety of reasons ranging from failure to bring suit to difficulty overcoming employers' defenses. ${ }^{218}$ But as industrial accidents were on the rise around the turn of the twentieth century, and it grew clear that workers may not be adequately compensated for the risks of occupational injury through their wages, the failures of tort law remedies became politically and socially unacceptable..$^{219}$ Workers' compensation laws were adopted nationwide to provide injured workers a less expensive mechanism of swift, certain compensation by moving the system out of court and eliminating any requirement to prove fault. ${ }^{220}$ Workers are not necessarily made whole and there is no compensation for pain and suffering or other noneconomic damages, nor any mechanism for punitive damages, which benefits employers. But workers' medical care is fully covered, as is some significant fraction of wage loss; in the event of death, survivors receive income and burial benefits. ${ }^{221}$ In addition, since employers pay all benefits, either directly or through insurance, the system forces them to internalize the cost of injuries incidental to their business. ${ }^{222}$ Unfortunately, these goals are not always perfectly achieved, particularly since disputes can remain regarding an injury's job-relatedness and the extent of disability, necessitating litigation. ${ }^{223}$

It may not be flawless, but the fact remains that on the whole, injured workers are more protected by the law than injured subjects, even if they recover less than they might if successful in court. Moreover, the same goals and problems driving the workers' compensation system seem similarly applicable to the research context. In fact, a "series of national advisory committees convened

example, employers with very few employees may not be covered, and non-employee workers such as volunteers may be. See infra, Part IV.B.4.

217 See Wash. Metro. Area Transit Auth. v. Johnson, 467 U.S. 925, 931 (1984) (describing the workers' compensation quid pro quo); Ellen R. Peirce \& Terry Morehead Dworkin, Workers' Compensation and Occupational Disease: A Return to Original Intent, 67 OR. L. REv. 649, 653 (1988).

218 Joan T.A. Gabel et al., The New Relationship Between Injured Worker and Employer: An Opportunity for Restructuring the System, 35 AM. Bus. L.J. 403, 405 (1998).

219 Peirce \& Dworkin, supra note 217 , at $652,655$.

220 Id. at $652-53$.

221 Staff of H. Comm. on Ways \& Means, 110Th Cong., 2008 Green Book: Background Material and Data on the Programs Within the Jurisdiction of the Committee on Ways AND MEANS, at sec. 15 (Comm. Print 2008), http://democrats.waysandmeans.house.gov/sites/ democrats.waysandmeans.house.gov/files/documents/wcss8.pdf (section on "Workers' Compensation").

222 Peirce \& Dworkin, supra note 217, at 653-54.

223 See, e.g., Gwen Forte, Rethinking America's Approach to Workplace Safety: A Model for Advancing Safety Issues in the Chemical Industry, 53 CLEv. ST. L. REv. 513, $522-23$ (2005); Mariner, supra note 212, at 122; Pike, supra note 212, at 46-47, 48, 49. 
to consider the obligations owed in the event of research-related injury have concluded repeatedly that injured research participants are entitled to compensation for their injuries, that the tort system provides inadequate remedy, and that the United States should consider some form of no-fault compensation."224 Indeed, unlike payment for participation, which is the source of substantial controversy, the contested question regarding care and compensation for injured subjects is not so much about desert as about scope and logistics.

Most commenters agree that there is an obligation to ensure that subjects do not individually bear the costs of medical care required to treat harms directly resulting from their research participation, without regard to fault. ${ }^{225}$ There is less agreement, however, as to whether there is any obligation to compensate subjects for economic and noneconomic harms beyond the costs of care. ${ }^{226}$ And there is even less agreement as to whether regulatory intervention is needed to ensure that obligations to injured subjects are satisfied, and if so, what the ideal intervention would look like. ${ }^{227}$ Some have suggested the workers' compensation model, ${ }^{228}$ and since the question here is whether there is any compelling reason to treat subjects differently from other protected workers, workers' compensation will be our focus.

224 Pike, supra note 212, at 10.

225 See, e.g., IOM, supra note 213, at 193; Hazel Beh, Compensation for Research Injuries, IRB: ETHICs \& HUM. Res., May-June 2005, at 11, 12; Mariner, supra note 212, at 117; Pike, supra note 212; Resnick, supra note 31, at 286; Ethical and Policy Issues in Research Involving Human Participants, NAT'L BIOETHICS ADVISORY COMM'N (NBAC) 123 (2001), http://bioethics.georgetown.edu/nbac/human/overvoll.pdf; International Ethical Guidelines for Biomedical Research, COUNCIL FOR INT'L ORGS. OF MED. SCIS. (CIOMS) 78-79 (2002), http://www.cioms.ch/publications/layout_guide2002.pdf; Moral Science, supra note 17, at 62 and app. IV; World Med. Ass'n, World Medical Association Declaration of Helsinki: Ethical Principles for Medical Research Involving Human Subjects (Oct. 19, 2013), http://jama.jamanetwork.com/article.aspx?articleID=1760318.

226 For arguments in favor of compensation of economic loss beyond the costs of care, see IOM, supra note 213, at 193; Scott, supra note 214, at 424; CIOMS, supra note 225, at 78. . See also Ministry of Health and Family Welfare (Dep't of Health) Notification, 2013, Gazette of India, pt. II, sec. 3(i) (Jan. http://www.elsevierbi.com/ /media/Supporting\%20Documents/Pharmasia\%20News/2013/Februar y/Clinical\%20Trials\%20Compensation\%20Guidelines.pdf (going to extreme lengths to demand care and compensation for injured subjects).

227 See, e.g., Lewin Group, Final Report: Care/Compensation for INJURIES In CliniCal RESEARCH 21 (2005); Moral Science, supra note 17, at 64-70; Steinbrook, supra note 213, at 1873.

228 Bernard R. Adams \& Marilyn Shea-Stonum, Toward a Theory of Control of Medical Experimentation with Human Subjects: The Role of Compensation, 25 CASE W. RES. L. REV. 604, 637-38 (1975); Beh, supra note 225, at 13; Elliott \& Abadie, supra note 45, at 2317; Scott, supra note 214, at 424; Irving Ladimer, Clinical Research Insurance, 16 J. CHRONIC DISEASES 1229, 1233 (1963); LEwIN GrouP, supra note 227, at 19; Resnick, supra note 31, at 283-85; David B. Resnick, Liability for Institutional Review Boards: From Regulation to Litigation, 25 J. LEG. MED. 131, 18283 (2004). Other approaches have also been suggested. See Moral Science, supra note 17, at 64; Pike, supra note 212, at 47-53. 
So, is there any such reason for differential protection? The Presidential Commission for the Study of Bioethical Issues, the most recent national body to take up this question, implies that the answer is no, at least as an ethical matter. Although it refused to adopt the idea of subject as wage-earner, ${ }^{229}$ the Commission noted that if subjects are employees in a dangerous job, it would be unjust to exclude them from a form of workers' compensation available to employees in other industries. ${ }^{230}$ The Commission did not, however, go so far as to endorse the workers' compensation model for HSR, or any change at all to the status quo. Instead, it argued that before any compensation scheme can be implemented in this realm there are questions regarding "the scope of any possible coverage, the delineation of qualified harms, mechanisms for determination of causation and qualification, relation to the tort system, the need for any special public or private insurance, and how the current nonsystematic approach to this issue functions in practice.,"231 Each of these issues is addressed in the sections below, but none provides the sort of relevant difference that can justify the disparity between the legal protections offered to injured workers and the lack of such protections for injured subjects.

\section{Scope, Need, and Burden}

With regard to scope of coverage, workers' compensation goes beyond what is currently agreed on (albeit not mandated) for injured subjects, but it does not go too far. This is because the same arguments that support protecting subjects from shouldering medical costs on their own seem to support protecting them and their dependents from fully bearing the weight of lost earnings, just as workers' compensation does. First, even though subjects may benefit financially or therapeutically from research, these benefits may not fully compensate for the risks they face, and even if they do, society and others also reap the benefits and should not be allowed to free-ride. Moreover, financial losses of all types are among risks to subjects that can be minimized, and beneficence and nonmaleficence support a system of compensation. Finally, recruitment will potentially benefit if subjects know they will not be left to face financial risks completely on their own. ${ }^{232}$ Thus, the scope of workers' compensation coverage for both medical costs and a portion of lost wages - seems to be the

229 Moral Science, supra note 17, at 119 n.103.

$230 \mathrm{Id}$. at 61.

231 Id. at 62 . Note that the Commission's charge was specific to federally-funded research.

232 Beh, supra note 225, at 12; Moral Science, supra note 17, at 119 n.103, Pike, supra note 212 , at 19-20,56; Resnick, supra note 31, at 282; see also VanderWalde \& Kurzban, supra note 26, at 545 (noting that the arguments in support of compensating subjects for research-related injury include encouraging research participation, relieving social discontent, fulfilling moral obligations to subjects, ensuring a just social distribution of resources, and incentivizing researchers to be careful with risk/benefit analyses). 
very minimum level of appropriate compensation for injuries in the HSR setting. $^{233}$

There are, however, two possible, mutually exclusive reasons not to implement a similar legal compensation system for injured subjects: (1) such a system is unnecessary because the needs of injured subjects are already being adequately satisfied through a patchwork of alternate mechanisms; or (2) such a system would be unduly burdensome on the research enterprise. ${ }^{234}$ The first, if true, would seem to be a relevant difference justifying stronger (or more formal) protections for injured workers than injured subjects, given that workers' needs were not adequately satisfied in the absence of legally mandated compensation. On the other hand, the second, even if true, would require some additional argument to explain why the burdens imposed on research by such a compensation scheme would be more problematic than the burdens imposed on other endeavors for which workers' compensation is required. However, since these are at least partly empirical claims, it is best to start with the empirical data.

First, it appears likely that injured subjects are not in fact being adequately compensated in the absence of a formal compensation system. More data are needed, but a 2005 study of over 100 academic medical center policies concluded that a subject's own health insurance serves as the "primary vehicle" for covering the cost of research-related injuries. ${ }^{235}$ Of course, not everyone has health insurance, and even if the Affordable Care Act and state initiatives are successful in achieving more universal coverage, policies vary in their inclusions and exclusions, copays, deductibles, and limits. More importantly, even if all health insurance covered clinical trial injuries, ${ }^{236}$ two problems would remain: injured subjects would still be paying for their own care via copays and other fees, and more importantly, it would remain health insurance, which of course does not cover other economic damages an injured subject may incur. Yet the study found that no institution or sponsor was offering to compensate injured subjects for lost wages or pain and suffering. ${ }^{237}$ And with regard to medical care, only $16 \%$ of the policies prospectively indicated a plan to provide free care or treatment for

233 One substantial concern is that requiring compensation for lost wages will drive the exclusion of high wage subjects from research and increase the recruitment of low wage subjects, with attendant justice issues. Dickert \& Grady, supra note 51 . This problem may be mitigated by capping wage recovery, precisely as workers' compensation does, although additional intervention may also be necessary.

234 Moral Science, supra note 17, at 67-68.

235 LEWIN GROUP, supra note 227 , at ES-3. The policies in question were generally sample informed consent forms and other information available on the web sites of major medical centers. Id. at 4 .

236 The Patient Protection and Affordable Care Act requires health insurers to pay for routine costs of care delivered in clinical trials, but it is unclear whether that includes care for study-related injury. Carmen Phillips, Insurance Coverage Expanding for Cancer Clinical Trials, NCI CANCER BULL. (May 18, 2010), http://www.cancer.gov/ncicancerbulletin/051810/page5.

237 LEWIN GROUP, supra note 227. 
injured subjects, with an additional $10 \%$ billing a subject's insurance first, but providing free care or treatment to those without coverage. ${ }^{238}$

A similar study found that of medical schools with template language for industry-sponsored research available on their websites, $61 \%$ declare that the industry sponsor would pay the medical expenses of research-related injury. In contrast, when there is no industry sponsor, only $22 \%$ of the schools offer some form of financial support, and half of those limit coverage to emergency medical care. In addition, $72 \%$ of medical school consent forms specifically rule out the possibility of additional monetary compensation, as distinguished from free or reimbursed care, and no schools explicitly offered such compensation. ${ }^{239}$

That being said, these policies - which are themselves only a limited sample - may not necessarily reflect what happens after an injury actually occurs, when sites may be more generous than their policies dictate. ${ }^{240}$ And representatives of the pharmaceutical industry have recently asserted that most industry-based clinical research sponsors voluntarily or contractually agree to carry insurance to compensate individuals injured in trials, although this is not required by law. ${ }^{241}$ Thus, on the most generous analysis, it may be the case that at least some injured subjects are in fact being adequately cared for and/or compensated for their care without having to reach into their own pockets, albeit on an ad hoc basis. Nonetheless, combining the available data with what we know about the obstacles an injured subject would face in court, the same is almost certainly not true for other economic costs of research-related injury. Accordingly, the lack of necessity argument likely fails as an empirical matter, pending further data.

However, it is important to recognize that having already established as the starting point that differential protection of subjects and workers requires justification, the onus should fall on those who claim that injured subjects do not need a workers' compensation system to demonstrate that to be the case. In other words, in the absence of complete data, the default should be to extend a workers' compensation system to injured subjects, rather than waiting until the data indicates such a system is needed. Similarly, the fact that there is little systematic and current information about the severity, frequency, and type of injuries that subjects experience and their costs ${ }^{242}$ does not itself provide a reason to reject a compensation system for injured subjects until affordability has been established.

238 Steinbrook, supra note 213, at 1872.

239 Michael K. Paasche-Orlow \& Frederick L. Brancati, Assessment of Medical School Institutional Review Board Policies Regarding Compensation of Subjects for Research-Related Injury, 118 AM. J. MED. 175, 177 (2005). Medical schools' IRB websites were examined for suggested text for informed consent documentation, which was then surveyed for text related to injury and compensation.

240 LEWIN GROUP, supra note 227; Steinbrook, supra note 213, at 1873.

241 Moral Science, supra note 17, at 66.

242 IOM, supra note 213, at vii-viii, 191-192; LEWIN Group, supra note 227, at ES-1, 2; Mariner, supra note 212, at 118; Scott, supra note 214, at 419-20; Steinbrook, supra note 213, at 1872. 
But even if there were evidence that such a system would be very costly, hindering research more than the prospect of litigation does at present-which there is not ${ }^{243}$ - that would still not necessarily suffice to justify the status quo, as some have claimed. ${ }^{244}$ This is because although burden is not completely extraneous to the workers' compensation analysis, it is only minimally relevant. Only very small employers are excluded from the law's requirements, and only in some states. ${ }^{245}$ Moreover, concern for cost or burden does not usually limit the workers' compensation claims of nonprofit employees or others who also may be doing socially valuable work. ${ }^{246}$ Thus, as was the case with regard to unrestricted subject payment, in order for cost to justify a refusal to protect injured subjects to the same extent as injured workers, it would have to be demonstrated that research progress is more critical than progress in other areas that might be affected by workers' compensation requirements. Bearing that possible caveat in mind, no convincing case exists thus far for differential treatment between the two groups.

\section{Covered Harm and Causation}

With these broad issues of scope, need, and burden resolved, the next question is whether there are any details of the workers' compensation system that would render a similar approach for injured subjects unworkable, since of course this would be a legitimate reason to protect subjects differently. Ultimately, some tweaking would be needed, but there is nothing so inherently different about the research context that a system of guaranteed and systematic compensation for injury ought to be rejected.

As for the types of harm that qualify for payment, workers' compensation seems to be a mixed fit for research. First, it fits well with regard to covering only those injuries that would result in documentable financial loss, and not

243 Serious research injuries are likely to be few and manageable, suggesting that the cost of care will be low and injuries will not keep subjects out of work for long. LEWIN GROUP, supra note 227, at ES-2, 32-33; Mariner, supra note 212, at 118; Pike, supra note 212, at 60-61; Resnick, supra note 31, at 265; Steinbrook, supra note 213 , at 1873 . Nonetheless, a system of guaranteed compensation for subjects would almost certainly be more expensive than the status quo, since nofault compensation plans "may help reduce the number of large awards to subjects [awarded through the tort system] only at the expense of increasing the number of small awards." Resnick, supra note 31 , at 284 . But importantly, this equation does not account for how research is currently hindered by costly defensive behavior generated by fear of litigation that may never come to pass or be successful.

244 See Beh, supra note 225, at 12; LewIN Group, supra note 227, at 1-2; Moral Science, supra note 17, at 67; Resnick, supra note 31, at 267.

245 Workers Compensation Laws - State by State Comparison, NAT'L FED'N OF INDEP. BUS., http://www.nfib.com/legal-center/compliance-resource-center/compliance-resourceitem/cmsid/57181 (last visited Nov. 22, 2013).

246 Bazil Facchina et al., Privileges and Exemptions Enjoyed by Nonprofit Organizations, 28 U.S.F. L. REV. 85, 117 (1993). 
minor problems like transient nausea likely to occur in a great deal of trials. ${ }^{247}$ Second, coverage of harms without regard to fault appears to be appropriate for HSR, given that none of the reasons articulated above for cost shifting away from injured subjects depends on fault or the lack thereof. ${ }^{248}$ Moreover, no-fault systems can have a variety of benefits such as speed, cost-effectiveness, and congeniality that would be beneficial in the research setting, and nearly every country that sponsors, hosts, or conducts substantial amounts of research - other than the U.S. - has implemented a no-fault compensation system for researchrelated injury, demonstrating feasibility. ${ }^{249}$

However, the fact that workers' compensation covers harms arising out of and in the course of work is likely too broad, at least for some subjects. This is because those participating in therapeutic or prevention research might have experienced harms in clinical care that would have been similar in type or magnitude to those caused by research. Although these harms would meet the workers' compensation standard, compensating the subject looks like a windfall; this should not be a qualified harm. ${ }^{250} \mathrm{~A}$ related issue is that all effective therapies and preventative interventions have benefits and drawbacks, such that a subject in a therapeutic or prevention study might be benefited in one way and injured in another. ${ }^{251}$ Ultimately, the workers' compensation standard for compensable injury is not equipped to handle this sort of problem because it is meant to remedy pure harms. Countervailing medical benefits and harms are likely to be common for HSR, however, and really cannot be ignored.

For subjects in therapeutic or prevention research, then, qualified harms must be more circumscribed than they are for purposes of worker's compensation. Rather than all injuries arising out of and in the course of research, qualified harms should be limited to those different or worse than what subjects could have expected in clinical care, and within that subset, limited to net harms. ${ }^{252}$ In addition, net harms should not be discounted on the basis of financial benefits (i.e., any payment a subject receives for participating), which is consistent with the fact that workers are compensated for work-related injury regardless of how much they make.

The research setting also poses other difficulties, but they are not necessarily unique. For example, when patients become subjects, it may be difficult to distinguish whether the symptoms experienced are compensable harms caused by the research or whether they are just the consequence of the subject's underlying

247 Pike, supra note 212 , at 57.

248 Beh, supra note 225, at 12; Moral Science, supra note 17, at 63.

249 Pike, supra note 212 , at 46.

250 See Adams \& Shea-Stonum, supra note 228, at 642; Pike, supra note 212, at 46.

251 See Moral Science, supra note 17, at 69 (noting that it is necessary to determine whether compensable research injury should include side effects that follow an effective therapeutic intervention); VanderWalde \& Kurzban, supra note 26, at 546 (questioning whether it is a harm when an experimental intervention lengthens life but causes other side effects).

252 Ackerman, supra note 28, at 3 . 
condition. ${ }^{253}$ However, a determination of research-relatedness must already be made for purposes of reporting adverse events to regulatory agencies and IRBs, so this problem is familiar and cannot be avoided. ${ }^{254}$ It is also already being addressed by the research institutions and handful of regulatory policies that currently provide or require compensation for study-related injury. ${ }^{255}$ Moreover, similar questions can arise for workers' compensation, ${ }^{256}$ particularly given its coverage of occupational disease that may be less obviously linked to the workplace because it develops over time and/or occurs in the general population as an ordinary disease of life. ${ }^{257}$ Recovering monetary costs in such cases is not necessarily easy, ${ }^{258}$ but the point is that factual issues of causation are not foreign to workers' compensation or to research. Thus, standing alone, difficulty in establishing causation for research-related injury is not a reason to treat injured subjects differently. ${ }^{259}$ And, importantly, for some research-related injuries, causation will be readily apparent.

\section{Funding, Tort Preemption, and Additional Concerns}

There remain a few additional reasons to suggest that even though injured subjects should be compensated, the workers' compensation mechanism might not be the right approach. First, perhaps the fact that medical research redounds to the public benefit ${ }^{260}$ suggests that unlike the workers' compensation system, which is funded by employers, the compensation system for injured subjects should be publicly funded. ${ }^{261}$ But many companies perform work that is socially valuable and still remain directly responsible for workers' compensation coverage. There is also a very clear sense in which compensation for subjects' injuries will be paid by the public, despite being paid first by those conducting the research: if research is conducted with federal money, compensation would come out of tax revenues, and if research is privately-sponsored, the cost of compensation would be rolled into the prices of medical products. ${ }^{262}$

253 See Alexander M. Capron, When Experiments Go Wrong: The U.S. Perspective, 15 J. CliniCAL ETHICS 22, 25 (2004); LeWIN Group, supra note 227, at 33; IOM, supra note 213, at 193; Mariner, supra note 212, at 121; Pike, supra note 212, at 28, 56; Resnick, supra note 31, at 266; Steinbrook, supra note 213, at 1872; VanderWalde \& Kurzban, supra note 26, at 546.

254 Pike, supra note 212, at 54-55.

255 See, e.g., Moral Science, supra note 17, at $122 \mathrm{n} .117$ (describing institutional compensation programs at the University of Washington and elsewhere).

256 See Resnick, supra note 31, at 266 (recognizing that courts and workers' compensation panels have to deal with complex causation problems on a routine basis).

257 Subjects' injuries may also be latent.

258 See generally STAFF OF H. COMM. ON WAYs \& MEANS, supra note 221, at 2; Peirce \& Dworkin, supra note 217 , at 659.

259 See, e.g., Pike, supra note 212 , at 56.

260 Mariner, supra note 212, at 121; Moral Science, supra note 17, at 58-60.

261 See Adams \& Shea-Stonum, supra note 228, at 640-41.

262 See VanderWalde \& Kurzban, supra note 26, at 545. 
What about the issue of tort preemption? Some have suggested that injured subjects should have the option of accepting no-fault compensation and waiving their right to sue, or waiving their right to no-fault compensation and suing instead. ${ }^{263}$ This would give subjects who are likely to be undercompensated by the no-fault scheme a chance to do better, but it is unclear why subjects should get this opportunity when other workers do not. Perhaps the difference is that whereas subjects are unlikely to be at fault for their injuries, workers' compensation as the exclusive remedy for workplace injury despite employer fault was a concession to employers who would be responsible for payment despite employee fault. ${ }^{264}$ Nonetheless, the fact remains that injured subjects would be able to recover even in the absence of any fault whatsoever. Thus, those conducting research have a similar argument that they should not also have to face greater liability when they are in fact at fault.

In addition, there is a sense in which a single system for compensating injured subjects is fairer, since similarly injured subjects will be compensated similarly without regard to their sophistication to navigate the tort system, for example. Another potentially attractive feature of no-fault compensation paired with tort preemption is that it could increase subject trust and solidarity with researchers by sending a clear message: you will be taken care of, there is no need to fight to get what you are rightfully owed, and there is no room for adversity in the research relationship. ${ }^{265}$ There is some concern that an exclusive no-fault approach will be less able to deter bad behavior, ${ }^{266}$ but eliminating the specter of negligence liability may help minimize the defensive posture that has come to predominate the culture of HSR, reflected in everything from legalistic consent to overly nit-picky IRB review. ${ }^{267}$ That said, however, it would be appropriate to preserve the opportunity to sue in the event of intentional or egregious behavior, which some workers' compensation laws allow. ${ }^{268}$

263 See Beh, supra note 225, at 12, 13; Mariner, supra note 212, at 119; Pike, supra note 212, at 49; Resnick, supra note 31, at 283. This is how the National Vaccine Injury Compensation Program works. See Vaccine Injury Compensation Program (VICP), NAT'L VACCINE INFo. CENTER, http://www.nvic.org/injury-compensation.aspx (last visited Nov. 22, 2013); Beh, supra note 225 , at 13 .

264 Adams \& Shea-Stonum, supra note 228, at 639.

265 On the other hand, it is possible that tort preemption could have the unintended consequence of scaring away potential subjects who are wary of relinquishing their right to sue. And the workers' compensation system itself can become adversarial, as previously noted. See supra note 223 and accompanying text; see also ROBERT A. KAGAN, ADVERSARIAL LEGALISM: THE AMERICAN WAY OF LAW 130 (2001).

266 Adams \& Shea-Stonum, supra note 228 , at 643.

267 See IOM, supra note 213 , at $189,122,178,181$; NBAC, supra note 225 , at $13,62,117$; see also Resnick, supra note 31, at 283 (explaining that a no-fault system may improve systems and procedures for preventing injuries by encouraging open communication).

268 See, e.g., Workers' Compensation: Can I Sue My Employer Instead?, FIndLaw, http://injury.findlaw.com/workers-compensation/workers-compensation-basics-overview/workerscomp-sue-employer.html (last visited Nov. 22, 2013); Workers' Compensation Agency, Frequently Asked Questions, Mich. DeP'T LiCENSING AND REG. AFF., http://www.michigan.gov/wca/0,4682,7- 
Other possible reasons for differential approaches for injured workers and injured subjects can also be rejected. Most commentators maintain that subjects' consent to research participation cannot waive their moral right to compensation for injury, ${ }^{269}$ and although consent to work may now take the existence of workers' compensation into account as part of what is being agreed to, workers' consent did not previously vitiate their moral claims to implementation of such a system. It also does no work to point out that some subjects are motivated by their own self-interest ${ }^{270}$ since the same is true of workers. Finally, there is no more need for concern that a compensation system would be viewed as a license to embark on riskier research than it would be viewed as a license to permit more dangerous workplaces, ${ }^{271}$ and the same safety and review standards would remain in place regardless of compensation for injury.

\section{Unpaid Subjects}

Although the preceding discussion has laid the case for compensating injured subjects and injured workers similarly, one important question remains. Since unpaid workers - volunteers - are often excluded from workers' compensation coverage as nonemployees, should the same be true for unpaid subjects?

There are generally two types of unpaid subjects, the pure altruist and the subject induced to participate by nonmonetary benefits such as possible therapeutic improvement. The latter resembles the unpaid intern seeking professional advancement in the sense that both are volunteering primarily for their own purposes and are remunerated in an important but non-monetary way. Moreover, both may make important contributions to the projects in which they are involved. ${ }^{272}$ Some states specifically exclude interns from workers' compensation coverage, but elsewhere, courts and administrative boards have granted them benefits, which seems to be the right approach given interns' likely lack of bargaining power and the problems with tort litigation described above. ${ }^{273}$ That same protection should apply to the unpaid benefit-seeking subject,

191-27210-41833--F,00.html (last visited Dec. 4, 2013); Workplace Injury: When You Can Sue Outside of Workers' Compensation, NoLo, http://www.nolo.com/legal-encyclopedia/workplaceinjury-lawsuit-sue-30334.html (last visited Nov. 22, 2013).

269 Adams \& Shea-Stonum, supra note 228, at 609; James F. Childress, Compensating Injured Research Subjects: The Moral Argument, 6 HASTINGS CENTER REP. 21 (1976); IOM, supra note 213, at 191; Moral Science, supra note 17, at 58-60; Pike, supra note 212, at 20-21; Scott, supra note 214, at 421. But see Steinbrook, supra note 213, at 1872 (noting the contrary view that "routine compensation is not required because subjects are made aware of the risks through the informed-consent process, understand them, and voluntarily agree to participate").

270 See Beh, supra note 225, at 12.

271 See Adams \& Shea-Stonum, supra note 228, at 641 n.95-96.

272 But note that this may necessitate payment under the Fair Labor Standards Act. See supra note 167 and accompanying text.

273 Mark Schappert, Employers' Internship Toolkit (2005), Le MOYNE C. (Aug. 2005), http://www.lemoyne.edu/Portals/11/pdf_content/career_services/INTERNSHIP_TOOLKIT.pdf. 
considering that all of the same rationales described above for offering compensation for research-related injury hold true, and also because these subjects likely depend on the research in some way that renders it difficult for them to negotiate for such compensation on their own. ${ }^{274}$

On the other hand, altruistic unpaid subjects pose an interesting paradox. They could presumably walk away from research opportunities with ease if they (1) understood the likelihood and potential severity of research injury, and that they would be on their own in the event injury occurs, and (2) found that to be unacceptable. This suggests that no intervention is really needed, although some have questioned whether the first assumption is really true. ${ }^{275}$ But even if it is, failing to mandate compensation when these subjects are injured seems to contradict the fact that altruists have the greatest moral claim to such compensation - after all, they are taking on risks and burdens exclusively for others. Shouldering the cost of injury may be part of the gift such altruists are willing to make, but it does not seem reasonable to expect altruists to either make such a sacrifice or refrain from research participation, especially when others who made lesser sacrifices (in the sense of having greater self-interest) would be provided compensation. Then again, this is precisely what happens in some cases. For example, volunteers helping to build a house for Habitat for Humanity might have to sign a waiver and release of liability explicitly recognizing that they are not covered by workers' compensation insurance, even though a construction employee doing exactly the same thing while getting paid would be covered. $^{276}$

What to do, then, with the true volunteer subject? Although it would not be outrageous or inconsistent to exclude them from mandatory no-fault compensation for injury, ${ }^{277}$ the more attractive option is to treat them like other volunteers who perform risky work that is highly socially valuable, offering protection as a matter of justice rather than to remedy inadequate bargaining power. For example, some states have chosen to recognize the "unselfish service" of volunteer emergency workers by covering them under workers' compensation laws. ${ }^{278}$ Given that altruistic volunteer subjects would face the

274 Mariner, supra note 212, at 123.

275 See Pike, supra note 212, at 44-45 (arguing that research subjects are not aware of the extent to which they are legally unprotected in the event of injury); see also Mariner, supra note 212 , at 117 .

276 See, e.g., Waiver of Liability, HaBitat for Humanity SMITH CounTY, http://www.smithcountyhabitat.org/volunteer-waiver-of-liability.html (last visited Nov. 22, 2013). However, some organizations will voluntarily offer some protection to volunteer workers. See, e.g., Frequently Asked Questions, Volunteering: General Questions, HABITAT FOR HUMANITY GREATER Bos. http://www.habitatboston.org/faq.html (last visited Nov. 22, 2013).

277 James G. Hodge, Jr. et al., The Legal Framework for Meeting Surge Capacity Through the Use of Volunteer Health Professionals During Public Health Emergencies and Other Disasters, 22 J. CONTEMP. HEALTH L. POL'Y 5, 51 (2005).

278 See, e.g., Volunteer Firefighter's and Volunteer Ambulance Worker's Guide to Workers' Compensation Benefits, N.Y. WORKERS' COMP. BD., http://www.wcb.ny.gov/content/main/ 
same difficulties recovering in tort as other injured subjects, and given the potential value of limiting liability in the research setting, as well as the symbolic importance of protecting those engaged in socially valuable activities, all types of research subjects - paid and unpaid, healthy and patient, enrolled in therapeutic and nontherapeutic research - should be entitled to at least the same benefits guaranteed to injured workers under the workers' compensation system: no-fault compensation for at least the costs of medical care and lost wages resulting from their injuries. The HSR regulations should be revised accordingly. ${ }^{279}$

\section{Working Conditions and Inspections}

With substantial changes in order for subject compensation, next consider the differential extent to which the HSR regulations and those governing the workplace address day-to-day working conditions. At first glance, the difference seems striking, with employees granted a variety of more specific protections. But upon closer inspection, little regulatory change is needed for human subjects.

For obvious reasons, working conditions are of greatest concern to those subjects enrolling in confinement studies at inpatient research centers. These sites differ substantially with regard to quality of facilities, amenities, and staff, ${ }^{280}$ with the worst facing problems described starkly by one self-titled "professional guinea pig": "[o]vercrowding, no hot showers, sleeping in an easy chair, incredibly cheap shit for dinner, creepy guys from New York jails-all these are a poor man's worries . . . . Where are these things in the regulators' paperwork?"281

Although IRBs and HSR regulatory agencies have the authority to inspect trial sites, such inspections are rare (largely due to resource constraints). When they do occur, they tend to focus on things like recordkeeping, protocol deviations, and informed consent issues. ${ }^{282}$ Paper-based review of research is the

firefighters/VFAWLawIntro.jsp (last visited Nov._22, 2013); see also James G. Hodge, Jr. et al., $A$ Hidden Epidemic: Assessing the Legal Environment Underlying Mental and Behavioral Health Conditions in Emergencies, 4 ST. LoUIS U. J. HEALTH L. \& PoL'Y 33, 66 (2010); Rubinstein, supra note 86 , at 182 n. 174 .

279 In addition to a new provision in the HSR regulations mandating compensation for injury, the prohibition on exculpatory language would also need to be modified in light of tort preemption. Other legal changes may also be necessary as a result of the Anti-Deficiency Act and the Adequacy of Appropriations Act. For a discussion of these issues, see Pike, supra note 212, at 47-49, 59.

280 See Elliott, supra note 30; GUINEA PIG ZERO, supra note 27, at 16-28; JIM HOGSHIRE, SELL Yourself to Science: The Complete Guide to Selling Your Organs, Body Fluids, Bodily Functions and Being a Human Guinea Pig 9, 20-25 (1992); Ondrusek, supra note 27, at 9-10, 113-119.

281 Elliott, supra note 30 (quoting Robert Helms).

282 See FDA et al., Guidance for Industry: Oversight of Clinical Investigations - A RiskBased Approach to Monitoring, HHS 3 (Aug. 2013), http://www.fda.gov/downloads/Drugs/../Guidances/UCM269919.pdf ("Monitoring activities include communication with the . . . study site staff; review of the study site's processes, procedures, and records; and verification of the accuracy of data submitted to the sponsor."); 
norm, but most protocols contain little information on the physical aspects of the sites where research is conducted, and IRB members may not be independently familiar with them. ${ }^{283}$ Investigators are charged by FDA with generally protecting the rights, safety, and welfare of research subjects, ${ }^{284}$ but they have substantial discretion with regard to site conditions, which are not explicitly addressed by the HSR regulations. The same is true for study monitors selected by sponsors to oversee the conduct and progress of clinical investigations at the site level. ${ }^{285}$

In contrast, although the Occupational Safety and Health Administration (OSHA) also inspects a very small percentage of workplaces each year, ${ }^{286}$ its regulations and overall focus are heavily concerned with specific conditions on the ground. ${ }^{287}$ In fact, OSHA has a variety of requirements for the living quarters at temporary labor camps, ${ }^{288}$ as well as housing for certain agricultural workers. ${ }^{289}$ Moreover, its general duty clause requires employers to provide a place of employment "free from recognizable hazards that are causing or are likely to cause death or serious harm to employees." This requirement would be violated by an employer who does nothing to prevent or abate a recognized hazard of workplace violence, such as threats, intimidation, or other indicators. ${ }^{290}$

Of course, trial sites are not as risky in and of themselves as mines, factories, or other dangerous worksites, so similarly stringent inspection requirements would seem overly burdensome. But is the difference between the OSHA and HSR standards and regulations themselves problematic? Not really. First, to the extent that sites are the workplaces of uncontroverted employees - research staff - basic OSHA standards regarding things like means of egress, ventilation, sanitation, and fire protection ${ }^{291}$ must already be satisfied, and research subjects

Bioresearch Monitoring (BIMO) Metrics - FY '10, FDA (2010),
http://www.fda.gov/downloads/ScienceResearch/SpecialTopics/RunningClinicalTrials/UCM26185 5.pdf; Daniel R. Levinson, The Food and Drug Administration's Oversight of Clinical Trials, HHS (Sept. 2007), http://www.oig.hhs.gov/oei/reports/oei-01-06-00160.pdf; OHRP, OHRP's Compliance Oversight Procedures for Evaluating Institutions, HHS (Oct. 14, 2009), http://www.hhs.gov/ohrp/compliance/evaluation/ohrpcomp.pdf; ABADIE, supra note 27, at 155.

283 Elliott, supra note 30; Ondrusek, supra note 27, at 48-49, 113-119.

28421 C.F.R. $\S 312.60$ (2013).

28521 C.F.R. $\S 312.53$ (d). Note that the Common Rule does not impose specific obligations on sponsors or investigators, unlike the FDA regulations.

286 See Indicator 18: Occupational Safety and Health Administration (OSHA) Enforcement Activities, MD. DeP'T. HEALTH \& MENTAL HYGIENE, http://phpa.dhmh.maryland.gov/OEHFP/EH/SitePages/Health-Indicator-18.aspx (last visited Nov. 22,2013 ) (finding that OSHA inspected only $1.2 \%$ of all establishments under its jurisdiction in 2000).

287 See generally 29 C.F.R. pt. 1910 (2013)

28829 C.F.R. $\$ 1910.142$.

28929 C.F.R. $\S 500.130$.

290 Occupational Safety \& Health Admin. (OSHA), Workplace Violence: Enforcement, U.S. DEP'T LAB., http://www.osha.gov/SLTC/workplaceviolence/standards.html (last visited Nov. 22, 2013).

291 See generally 29 C.F.R. $§ 1910$. 
would be incidental beneficiaries of compliance and enforcement. Second, the health care facilities that may be used for research are heavily regulated ${ }^{292}$ and even if research is conducted at a stand-alone site not otherwise subject to specialized health care facility regulations, the site will still be subject to local building safety, sanitation, and fire codes. Indeed, it was violation of these requirements that led to the 2005 demolition of a trial site in Miami. ${ }^{293}$ Thus, the HSR regulations do not necessarily need to impose their own site-specific standards, which may be redundant, nor should HSR regulators step in to enforce standards that really ought to be enforced by other agencies.

Instead, the best approach to ensuring commensurate protection for workers and human subjects is to make sure that the designated authorities appropriately enforce the existing health and safety requirements applicable to research sites. It may also be necessary to ensure that stand-alone research sites are covered by appropriate health care facilities regulations, if they are not already. And it would be a reasonable compromise for the HSR regulations to require that IRBs receive certification or explicit assurance that facilities used for research purposes are in compliance with all applicable facilities codes, as OSHA does in some contexts. ${ }^{294}$ Finally, at an absolute minimum, the HSR regulations should make clear that the responsibility for protecting subject welfare includes not only consideration of study interventions but also study conditions, and should also explicitly protect subjects against retaliatory action for reporting violations. ${ }^{295}$ Some site level issues will certainly remain, since there is no worklaw requirement that supervisors be nice, that the food be good, or that entertainment options be provided (all of which are complaints that have been lodged by the subject community). However, these can be appropriately left to the market as they are far removed from actual safety concerns, and instead reflect the sorts of discomforts that are relatively commonplace in daily life.

\section{Collective Bargaining and Unions}

As a final point of comparison, consider that employees also have greater protection than research subjects with regard to their rights to concerted action and collective bargaining under the National Labor Relations Act (NLRA). At

292 See, e.g., Fla. Admin. Code AnN. r. 59A-3.081 (2013) (Physical Plant Requirements for General, Rehabilitation and Psychiatric Hospitals); 25 TEX. ADMIN. CODE $§ 1.133$, Subch. I (2013) (Hospital Licensing Physical Plant and Construction Requirements); JOINT COMmISSION, 2012 HOSPITAL ACCREDITATION STANDARDS (2011).

293 David Evans, Michael Smith, \& Liz Willen, Big Pharma's Shameful Secret, BloOmBerG MARKETS, Dec. 2005 (describing study conditions at SFBC International's Miami site); David Evans, SFBC Ordered to Demolish Miami Drug Test Center, Bloomberg (May 18, 2006, 4:10 PM), http://www.bloomberg.com/apps/news?pid=newsarchive\&sid=a3FrlL6PPXkc (describing conditions resulting in the site's demolition).

294 See, e.g., 29 C.F.R. $\$ 500.135$ (2013).

295See, e.g., Safety and Health Standards: Occupational Safety and Health, U.S. DEP'T LAB., http://www.dol.gov/compliance/guide/osha.htm (last updated Sept. 2009). 
first glance, it may appear that subjects are just as well protected via IRBs, if not more so, given that IRBs stand as the constant intermediary protecting the interests of subjects against those of researchers and sponsors. Further, although researchers and sponsors have no choice but to engage with IRBs, IRBs are under no obligation to "bargain" with those conducting the research; unlike bargaining representatives under labor law, IRBs can command and compel because their approval is legally required before research can proceed or continue.

It would be a mistake, however, to view IRBs as actually representing subjects in the way that unions represent employees. With the exception of research involving prisoners, the regulations do not require that any subjects be included on the board, or that subjects be consulted at all, and no one is charged with speaking on the subjects' behalf. ${ }^{296}$ The goal is only to protect them, and a mission to protect can be quite different from a mission to improve. Moreover, even though a subject can always bring his or her concerns to the IRB, there is no guarantee that the IRB's response will be what a subject had in mind; a complaint about low payment is unlikely to result in higher rates if a board is concerned about undue inducement, for example.

On the other hand, there is a growing trend toward community engagement in HSR, with the goal of providing communities greater ownership of and information about research projects. ${ }^{297}$ Thus, a number of trial networks and research sites now work with Community Advisory Boards (CABs) as a way to provide those affected by or involved in research at the local level a way of voicing their needs and concerns. ${ }^{298}$ Even this, however, is a far cry from the protection offered to employees by the right to bargain collectively. First, the community in question may include anyone bearing a stake in the research, from government representatives to patient advocacy groups to health care workers to subjects and their families. ${ }^{299}$ Second, and more importantly, while it may be good ethical practice to engage in community consultation, the regulations do not

29645 C.F.R. $\S 46.107 ; 21$ C.F.R. $\S 56.107$ (describing IRB membership requirements). For research involving prisoners, at least one member of the Board must be a prisoner or prisoner representative. 45 C.F.R. $\S 46.305$.

297 See, e.g., 1 Nat'l Bioethics Advisory COMm'N, ETHiCal and POlicy Issues in International Research: CliniCal Trials in Developing Countries, 30 (2001); UNAIDS, Good Participatory Practice: Guidelines for Biomedical HIV Prevention Trials (June 2011), http://www.unaids.org/en/media/unaids/contentassets/documents/unaidspublication/201 1/JC1853 GPP_Guidelines_2011_en.pdf.

298 See, e.g., Cmty. Recommendations Working Grp., Recommendations for Community Involvement in National Institute of Allergy and Infectious Diseases HIV/AIDS Clinical Trials Research, HIV VACCINE TRIALS NETWORK (Feb. 2009), http://www.hvtn.org/ community/CAB_Recommendations_Certified.pdf.

299 Id. at 6. 
require it outside the context of emergency research conducted without subject consent. $^{300}$

Ultimately, there is no requirement that anyone actually hear and consider the requests and demands of research subjects. If a subject attempted to negotiate greater benefits for those enrolled in a trial, he would not be entitled to legal protection against retaliation. ${ }^{301}$ Even if he were not penalized, researchers and sponsors would be under no obligation to negotiate with him or any other representative, and even if they wanted to, any agreements reached could be thwarted by the IRB. Then again, subjects would be under no obligation to follow any standards whatsoever in their negotiations.

Employees covered by the NLRA, in contrast, have the "right to selforganization, to form, join, or assist labor organizations, to bargain collectively through representatives of their own choosing, and to engage in other concerted activities for the purpose of collective bargaining or other mutual aid or protection... "302 Employers are prohibited from interfering with, restraining, or coercing employees in the exercise of these rights. ${ }^{303}$ The Act also protects both employees and employers against certain behaviors by labor organizations. ${ }^{304}$

To engage in collective bargaining, employees must come together to determine that they want a bargaining representative, and select one. If and once they have done so, both the employer and the representative have a legal obligation to bargain in good faith about wages, hours, and other conditions of employment, ${ }^{305}$ although this does not compel either party to agree to any proposal made by the other. ${ }^{306}$ Moreover, employees may strike (and employers may impose a lockout) in order to further their position, so long as they (or their representatives) remain engaged in good faith bargaining throughout. ${ }^{307}$

Employees are also protected in their right to refrain from organizing, joining a union, bargaining collectively, or engaging in other concerted

30021 C.F.R. $\$ 50.24(a)(7)(i)$; FDA et al., Guidance for Institutional Review Boards, Clinical Investigators, and Sponsors: Exception from Informed Consent Requirements for Emergency Research, HHS 25-34 (Apr. 2013), http://www.fda.gov/downloads/RegulatoryInformation/ Guidances/UCM249673.pdf.

301 As one website offering tips for subjects advises: "Don't circulate petitions (or sign them) protesting your pay, or restrictions on the unit .... Usually this behaviour will get you banned from the clinic in the future." Tips for Clinical Trials and Clinical Study Volunteers, GPGP.NET (2009), http://www.gpgp.net/tips.

30229 U.S.C. $\$ 157$ (2006).

30329 U.S.C. $\S 158(\mathrm{a})(1)$.

30429 U.S.C. $\$ 158(\mathrm{~b})$.

30529 U.S.C. $\S \S 158(a)(5),(b)(3)$, (d); Basic Guide to the National Labor Relations Act: General Principles of Law Under the Statute and Procedures of the National Labor Relations Board, NAT'L LABOR RELATIONS BD. (NLRB) 20 (1997), https:/www.nlrb.gov/sites/ default/files/documents/224/basicguide.pdf.

30629 U.S.C. $\S 158(\mathrm{~d})$.

307 Basic Guide to the National Labor Relations Act, supra note 305, at 3-5, 16. 
activities. $^{308}$ However, because a bargaining representative need only be designated by the majority of the employees in a bargaining unit, an individual who would have selected a different representative or chosen not to engage in collective bargaining at all is nonetheless stuck; all employees will be bound by any collective bargaining agreement negotiated by the representative. ${ }^{309}$ Another restriction on the "right to refrain" is that although applicants for employment cannot be required to be members of a union in order to be hired, and employees cannot be required to join or maintain membership in a union in order to retain their jobs, the NLRA does permit "union security" agreements in some cases. Thus, a union and an employer can make an agreement that requires employees to pay their share of "financial core" costs relating to the union's representational activities (short of actual membership) in order to retain their jobs. ${ }^{310}$ However, in a "right-to-work" state, which now describes nearly half of the U.S., employees may not be forced to even financially support a union. ${ }^{311}$

All things considered, even though subjects may have some greater freedoms than employees when it comes to negotiating, these are outweighed by the ability of employees to come together to achieve things they likely could not on their own, and to have a voice that must be heard by those in charge. ${ }^{312}$ But should subjects be leveled up with regard to collective bargaining and unionization, as some bioethicists have argued?

The idea appears intuitively appealing, considering the similarities between subjects and workers and the challenges they might face. For example, although the stated function of the NLRA is to help mitigate industrial strife that would otherwise burden or obstruct commerce if left unchecked, it also recognizes the "inequality of bargaining power between employees who do not possess full freedom of association or actual liberty of contract" and seeks to "restor[e] equality of bargaining power between employers and employees" as a way to protect commerce. ${ }^{313}$ The fact that research subjects are not currently guaranteed NLRA-type rights has clearly not brought commerce - or research - to a halt, so it may seem unnecessary to institute any change in this regard. However, that may be a testament to just how poor subjects' bargaining power truly is, rather

30829 U.S.C. $\$ 157$.

30929 U.S.C. § 159(a); Basic Guide to the National Labor Relations Act, supra note 305, at 8.

310 Basic Guide to the National Labor Relations Act, supra note 305, at 2.

311 Right to Work States, NAT'L RIGHT TO WORK LEGAL DEF. Found., http://www.nrtw.org/rtws.htm (last visited Nov. 6, 2013); "Right to Work" for Less, AFL-CIO, http://www.aflcio.org/Legislation-and-Politics/State-Legislative-Battles/Ongoing-State-LegislativeAttacks/Right-to-Work-for-Less (last visited Nov. 22, 2013).

312 This is not to suggest that the NLRA rights are perfect or perfectly enforced, and in fact many labor scholars have pointed out deficiencies and proposed solutions. See, e.g., Stephen F. Befort, Labor and Employment Law at the Millennium: A Historical Review and Critical Assessment, 43 B.C. L. REv. 351, 433-443 (2002). However, the rights themselves are more than what subjects have at present.

31329 U.S.C. § 151 (2006). 
than an indication that they are satisfied with the terms and conditions of the research opportunities they are offered. With the exception of true altruists, individual subjects generally hold the weakest position in the HSR relationship, and their position could be improved by collective action on a large enough scale. Thus, although the underlying purpose of the NLRA does not necessarily dictate extension of similar rights to research subjects, it certainly does not conflict with such extension.

Consider, however, the obstacles that would stand in the way of collective bargaining and unionization by most research subjects. With some limited exceptions, ${ }^{314}$ studies are usually developed and approved before any interaction with subjects occurs, and before subjects are even identified, so there is not yet anyone for those conducting the research to come together and bargain with, let alone anyone whose interests can be represented, except in the abstract. Subjects could decide to organize for improved terms and conditions once they have been enrolled, at which point they have improved bargaining power together given the sunken investment in their data, but by then, it is quite late to make any changes. More importantly, outside of confinement studies, they may never be in the same place at the same time or even know who else is in a study, which obviously makes the identification of common interests and the push to organize difficult. In addition, subjects may participate in research only once or just a few times, such that even though they have shared interests, they have no long-term investment in the hassle of organizing. ${ }^{315}$ Even if they could be assured protection against retaliation for concerted action, in order for such action to impose the desired bargaining pressure, the subjects would have to be willing to take some risk together, e.g., to strike until their demands are met. Subjects who just want the money or especially the potential therapeutic benefits may be unwilling to do so. ${ }^{316}$ Moreover, bargaining study-by-temporary-study would be terribly inefficient. If organization and bargaining had to occur at this level, it is very unlikely that the burdens would outweigh the benefits, and that enough subjects would have adequate motivation to take the necessary steps.

Given their greater durability than single studies, the research site or sponsor would seem to be the preferable locus of organizational activity, but that assumes there are some subjects who have a site- or sponsor-level interest, beyond single studies. That may be true for a subset of repeat and professional subjects, although their numbers may be inadequate to provide significant leverage, particularly given the difficulties they are likely to face identifying one another

314 For example, consider Greenberg v. Miami Children's Hosp. Research Inst., 264 F. Supp. 2d 1064 (S.D. Fla. 2003), where patients themselves initiated research on their rare disease and would likely have had relatively strong bargaining power (had they attempted to reach a clear agreement ex ante) by virtue of having something rare that researchers were interested in.

315 See Befort, supra note 94, at 170 (noting that many contingent workers do not see the benefits of union representation in the context of short-term employment).

316 ABADIE, supra note 27, at 58; see also GALL, supra note 75, at 110-111 (explaining the similar problem of organizing some commercial sex workers). 
and/or staying in contact once any given study is over. ${ }^{317}$ And even if they successfully negotiate terms to cover all studies at a given site, for example, there is the problem of free-riding, unless all subjects enrolling at that site are required to contribute in some way to the negotiating group.

Subjects' best bet would be to "organize the industry" along the lines of the Screen Actors Guild (SAG) and other performing arts unions, ${ }^{318}$ but this too would be tremendously challenging. Like subjects, actors are engaged in shortterm projects with a variety of different employers. To deal with these unique circumstances, SAG negotiates basic contracts with producers to establish minimum wages and working conditions for actors. ${ }^{319}$ Producers who want to hire SAG members must agree to the terms of a SAG contract, and actors who want to perform in a "Guild Signatory production" must generally either be SAG members or join within a certain period of time. ${ }^{320}$ Moreover, SAG members are bound by "Global Rule One," which dictates that "no member shall work as a performer or make an agreement to work as a performer for any producer who has not executed a basic minimum agreement with the Guild which is in full force and effect.. ${ }^{, 321}$ Failure to abide by this rule can lead to disciplinary action including expulsion.

Ultimately, actors want to be SAG members because otherwise their job prospects are limited and producers want to be Guild Signatories because otherwise their talent prospects are limited. Note that for the system to work, there must be a critical mass on at least one side of the equation: enough SAG members refusing to work for non-SAG producers that the producers are strongly motivated to deal, or enough SAG producers refusing to hire non-SAG members (within the limits of union security agreements) that the actors are strongly motivated to join. On the other hand, if enough producers refused to become Guild Signatories, the actors could work without joining SAG - in fact, SAG membership would hold them back because of Global Rule One - and if enough

317 Helms, supra note 5 ("The guinea pig workforce may be too fragmented and fluid to form even an unofficial union."); ABADIE, supra note 27, at 82-83 (explaining that once a trial is over, subjects usually do not remain in contact).

318 Others have also relied on the SAG model to demonstrate how diverse and nontraditional workers who might be difficult to unionize could successfully do so. See, e.g., Patricia Ball, Comment, The New Traditional Employment Relationship: An Examination of Proposed Legal and Structural Reforms for Contingent Workers from the Perspectives of Involuntary Impermanent Workers and Those Who Employ Them, 43 SANTA CLARA L. REV. 901, 938 (2002).

319 Acting in Your Interest, SCREEN ACTORS GUILD (SAG) 15 (2011), http://www.sag.org/files/sag/documents/Acting_In_Your_Interest_0.pdf.

320 Getting Started as an Actor FAQ: What Is a "Guild Signatory?", SAG-AFTRA, http://www.sagaftra.org/content/getting-started-actor-faq (last visited Nov. 22, 2013). It is important to recognize that this is a union security provision, however, and therefore is not absolute. See Bob Labate, The Mystery of Financial Core, Holland \& KNIGHT (Sept. 15, 2000),http://www.hklaw.com/publications/The-Mystery-of-Financial-Core-09-15-2000/; Get the Facts About Financial Core, SAG-AFTRA http://www.sagaftra.org/get-facts-about-financial-core (last visited Nov. 22, 2013).

321 Acting in Your Interest, supra note 319, at 5. 
actors refrained from membership, producers would have no reason to become Guild Signatories.

Putting this all together, in order for research subjects to engage in successful collective action to negotiate better terms for study participation, they could wait until a study is underway and then jointly threaten to quit - an unlikely scenario. Or they could adopt the SAG model by forming a union and requiring members to refuse to enroll in any study not covered by a union contract, which would include union security provisions. However, if sponsors and sites are able to enroll enough non-union subjects, they have no reason to sign a union contract, and the whole thing falls apart. Thus, the essential element is encouraging the critical mass of subjects to join. But is that possible?

Assuming that the right to refrain from union membership would be retained in the realm of HSR, which undercuts unions but preserves important individual freedoms, the most that could be required of subjects seeking enrollment in union studies would be satisfaction of financial core obligations to the union, not actual membership. ${ }^{322}$ In that case, fee-paying nonmember subjects could participate in union studies, as well as non-union studies because they would not be bound by the requirement imposed on members to refuse enrollment in non-union work. Moreover, in "right-to-work" states, even financial core status cannot be required. ${ }^{323}$ Since this clearly allows free-riding on the union's efforts, ${ }^{324}$ there are good arguments that it should not be allowed for HSR (or other types of work). However, even though there is not necessarily any legal right to be included in a research study, there might be a strong moral argument for treating participation in at least therapeutic studies as a "right-to-work" endeavor, the opportunity for which should not be denied on the basis of non-membership in a subjects' union, or non-payment, as the case may be. ${ }^{325}$ Indeed, research participation may be a patient's best hope for care, particularly if they have exhausted all other options and face a serious disease. Similarly, union membership itself would be problematic if it would technically preclude participation in a desirable, non-union therapeutic study through something like Rule One. Subjects likely to enroll in only a single study or for whom the therapeutic stakes are very high - namely, those for whom the worker analogy is the weakest - would obviously choose enrollment over union membership in this

322 See Commc'ns Workers v. Beck, 487 U.S. 735, 745 (1988); N.L.R.B. v. Gen. Motors Corp., 373 U.S. 734, 742 (1963).

323 See Michael M. Oswalt, Note, The Grand Bargain: Revitalizing Labor through NLRA Reform and Radical Workplace Relations, 57 DUKE L.J. 691, 700 (2007).

324 Id. at 701; see also Susan Guyett, Indiana Becomes 23rd "Right-to-Work" State, ReUTERS (Feb. 1, 2012, 5:29 PM), http://www.reuters.com/article/2012/02/01/us-unions-indianarighttowork-idUSTRE81018920120201.

325 See, e.g., Martha L. Elks, The Right to Participate in Research Studies, $122 \mathrm{~J}$. LABORATORY \& ClinICAL MED. 130 (1993) (arguing that it is important to protect subjects not only from the risks of research participation, but also to protect their interest in the benefits of research participation). 
case. And subjects motivated purely by altruism - also in the weak analogy camp - would likely see no need to come together for mutual protection in this way. Ultimately, each of these factors would conspire to weaken any attempt at subject unionism.

Repeat and professional subjects are the most likely candidates for successful unionization, as they have the most "skin in the game" and are the most likely to benefit from the entertainment industry approach. Given their concentration in nontherapeutic, early phase studies, there seems to be no moral argument in favor of a right-to-work approach, although as a scientific matter, limiting participation in any type of research to union members (or those paying membership fees) could be problematic in terms of generalizability and bias. Thus, it seems that union security agreements would be unacceptable across the board in the research context.

There are also a number of other barriers to achieving the critical mass of subjects necessary to get any sites or sponsors to agree to collective bargaining contracts. As noted above, subjects may be unwilling to refrain from enrollment or participation as an exercise of power intended to push a deal through, especially because there may be enough casual or one-time subjects available to replace them. Moreover, if HSR regulations are amended to lift payment restrictions and guarantee subjects a minimum wage, compensation for injury, and decent working conditions, some of their chief complaints will have been addressed, potentially cutting down on their motivation to organize. ${ }^{326}$ And although the Internet could help, ${ }^{327}$ there is the fundamental problem of organizing a group of relatively transient, potentially stigmatized subjects who may fear running in opposition to a significant source of their income. ${ }^{328}$ Perhaps most importantly, if critical steps are taken to preserve the integrity, generalizability, and validity of research results by limiting repeat participation, ${ }^{329}$ there will be even fewer subjects who would care enough to organize.

So what is the bottom line for the HSR regulations - are the various obstacles to collective action sufficient reason not to level subjects up? At the very least, subjects should have the freedom to face these obstacles head on, and therefore ought to have a protected right to engage in concerted activity, if they so choose, just like workers protected by the NLRA. ${ }^{330}$ In the labor context, this right is

326 See ABADIE, supra note 27 , at 58 (noting that subjects' pay is generally good compared to other opportunities, so subjects have reduced incentive to challenge industry).

327 Richard B. Freeman \& M. Marit Rehavi, Helping Workers Online and Offline: Innovations in Union and Worker Organization Using the Internet, (Nat'l Bureau of Econ. Research, Working Paper No. 13850, 2008), http://www.nber.org/papers/w13850.

328 See GALL, supra note 75, at 92-93, 189-218 (describing a number of barriers to organizing sex workers that apply with equal force to HSR).

329 See notes 187-190, supra, and accompanying text.

330 See Eli Naduris-Weissman, The Worker Center Movement and Traditional Labor Law: A Contextual Analysis, 30 Berkeley J. EMP. \& LAB. L. 232, 257 (2009). 
quite broad, ${ }^{331}$ as it should be for HSR. For example, sites and sponsors should be prohibited from discriminating against a subject or potential subject in enrollment or continued participation on the basis of that subject's present or former attempts to advocate on behalf of subjects, draw attention to subjects' concerns, inform subjects of their common interests and what they might be able to accomplish working together, and organize subjects for collective activity. Without these basic protections, subjects' bargaining power is limited to a degree beyond their inherent financial and/or therapeutic vulnerability. Of course, these concerted activities may fail to achieve subjects' goals, especially because individual subjects should also be free to avoid joining in, and those conducting the research would not be legally forced to give in to subjects' demands. But at least by protecting the right to act together or call others to action, subjects would have a good chance of being heard. Subjects aggrieved in their attempts to exercise this right should have recourse to the IRB and/or federal regulatory agencies overseeing HSR. ${ }^{332}$

The question of whether subjects ought to also be granted the right to bargain collectively through representatives of their own choosing is somewhat more complicated, however. Unlike protecting concerted activity, which would involve only the cost of enforcement, leveling up as to representative collective bargaining would involve the administrative costs and practical considerations of identifying appropriate bargaining units and conducting elections to determine whether a majority of subjects wish to unionize, and if so, who they want to represent them. ${ }^{333}$ Then again, these costs would only have to be incurred when the subjects have some chance of success, as when they can demonstrate that some threshold number supports representation, in which case the costs may be justified. ${ }^{334}$ The alternative path of persuading a site or sponsor to voluntarily recognize a subject bargaining representative after a showing of majority support seems preferable, ${ }^{335}$ but of course, may be difficult to achieve without the intervention of some third party.

Beyond the issue of resources, there may also be some concern that a collective bargaining approach would create a situation in which those conducting the research felt less responsibility for subject welfare, either because subjects would be viewed as adversaries ${ }^{336}$ or because subjects have a better means of protecting themselves. On the other hand, those conducting the research

$331 \mathrm{Id}$. at 259-61.

332 Similarly, the NLRA offers no private right of action.

333 What We Do: Conduct Elections, NLRB https://www.nlrb.gov/what-we-do/conductelections (last visited Nov. 22, 2013).

334 For example, before the NLRB will hold a representation election, at least $30 \%$ of employees in the relevant bargaining unit must have signed a petition showing interest. Id.

$335 \mathrm{Id}$.

336 GUINEA PIG ZERO, supra note 27, at 6 ("If we lab rats were to be taken under the regular labor laws and tried using traditional organizing methods, we'd end up with fewer freedoms, making less money, and we'd be lied to by the scientists more often."). 
would have to abide by the terms of any collective bargaining agreement, and at a more fundamental level, the very reason collective bargaining would have been necessary is that subjects felt others were not adequately protecting their interests. ${ }^{337}$

Ultimately, failure to grant subjects a right to representative collective bargaining may not be a substantial problem in practice, since they are likely to face so many obstacles to organizing in the first place, including the need to adopt a right-to-work approach in the research setting for the reasons described above. However, if they could successfully organize, this protection would be essential to getting those who conduct research to engage in good faith bargaining as a matter of course, rather than forcing subjects to threaten a strike in order to even get sites and sponsors to the bargaining table. Many other types of workers also face difficulty exercising their labor rights, and labor unions are on the decline in general, ${ }^{338}$ but this is not a reason to eliminate those rights or not to offer them in the first place. If anything, it is a reason to seek ways to make them more accessible. Further debate is in order, but for now, there appears to be no compelling reason to refrain from leveling up by granting subjects the full gamut of NLRA rights. ${ }^{339}$ The best mechanism for doing so remains an open question, ${ }^{340}$ but the first step of protecting subjects' concerted activity should be simple enough. And it is worth noting that large, public-minded funders of HSR might be able to play a role here, for example requiring that grantees recognize and engage with subject organizations who seek to negotiate, and perhaps even helping to facilitate subject organizing where barriers are likely to stand in the way of organic development. These funders could potentially set a new standard for ethical research engagement, as they have in other areas. ${ }^{341}$

337 A related issue is whether there would be any role for IRBs if subjects could collectively bargain. It is possible IRBs would still have an important function related to protecting community interests in sound science and the like, but it is unnecessary to substantially delve into this issue here given that collective bargaining is likely to occur so infrequently in the research setting.

338 GALL, supra note 75, at 225; Befort, supra note 312 , at 361-77.

339 Note, however, that even in the standard employment context there is widespread agreement that these rights are not adequately protected. See, e.g., Benjamin I. Sachs, Employment Law as Labor Law, 29 CARDOZo L. REV. 2685, 2694-2700 (2008).

340 See, e.g., Domestic Workers United et al., Domestic Workers and Collective Bargaining: A Proposal for Immediate Inclusion of Domestic Workers in the New York State Labor Relations Act, NAT'L DOMESTIC WORKERS AllianCE 12-13 (Oct. 2010), http://www.domesticworkers.org/sites/default/files/pdfs/collectivebargaining.pdf (discussing potential ways to allow domestic workers to engage in collective bargaining, including how bargaining units could be defined, that may be of interest as an analogy to HSR).

341 See, e.g., Guidance for Addressing the Provision of Antiretroviral Treatment for Trial Participants Following Their Completion of NIH-Funded HIV Antiretroviral Treatment Trials in Developing Countries, NAT'L INSTS. HEALTH, http://grants.nih.gov/grants/policy/antiretroviral/_(last updated June 9,2005 ). 
Considering the divergent interests of research subjects and those conducting the research, as well as issues of dependency and unequal bargaining power, features that generally motivate a variety of worker protections, there was already a strong case for leveling subjects up by revising the HSR regulations to incorporate certain protections from worklaw. This section strengthened that case in a number of areas by considering and rejecting possible reasons that worker protections would be inappropriate for research subjects.

Thus, with a few caveats regarding the continued ability to conduct essential research and certain inherent features of research injuries, the HSR regulations should permit subjects to be paid without regard to an upper limit, require that paid healthy subjects participating in nontherapeutic research be guaranteed some minimum wage, mandate that injured subjects be compensated for medical care and lost wages, extend consideration to site conditions, and protect subjects in their concerted activities and efforts at representative collective bargaining. Subjects need not be offered unemployment compensation, however, and ought to be encouraged to pursue more viable alternatives to unionization, such as the development of trade associations and other advocacy groups.

Where the regulations need revision, it clearly will not be appropriate to simply cut-and-paste from the relevant provisions protecting workers. Tailoring to account for the vagaries of HSR will be in order, but what has been established here is that those bioethicists advocating for worker protections in relatively abstract terms have been largely vindicated in the wake of rigorous legal and normative analysis.

\section{OUTSTANDING OBJECTIONS}

Before concluding, there are a handful of outstanding objections worthy of brief attention beyond those that have already been considered and dismissed above. First, as recognized at a number of points in the preceding analysis, worklaw as it currently exists is far from perfect - too many workers fall outside the scope of protection, minimum wages are too low, workers' compensation systems are flawed, union activity is not adequately supported, and US worklaws do not apply to workers at foreign sites. ${ }^{342}$ Thus one may take issue with the use of worklaw as the appropriate lodestar for human subjects research regulation. To be clear, however, nothing herein is intended to suggest that if we just treat subjects like workers, no further action will be needed. Again, the fundamental point is recognizing the similarities between the two groups and the consistency

342 Zatz, supra note 81 , at 58 n.3. On the question of international application, note that unlike worklaw, the U.S. HSR regulations do not simply defer to local standards, but rather apply equally whether research is conducted domestically or abroad (assuming the requisite jurisdictional link to the U.S.). See Moral Science, supra note 17, at 31-32. Thus, if the regulations are amended to add various worklaw protections as advocated herein, those protections would apply abroad as well. In this sense, international subjects would be "leveled beyond" their workplace counterparts. 
in treatment that those similarities demand. Thus, if worker protections are inadequate for workers, they ought to be improved, and for subjects as well. But that fact is no reason not to extend the protections that do exist to subjects; subpar protections are preferable to none at all.

A related objection suggests that even if subjects are like workers, they should not be compared to workers in legally permissible industries but rather to those engaged in illegal work, or work that is prohibited to be paid, such as commercial sex work. Thus, the argument goes, even when it appears that subjects are more protected than workers, they are in fact less protected than the relevant comparators who are shielded by outright prohibition. The strongest response to this objection is that many of those other transactions should not be prohibited at all, but rather carefully regulated - just like HSR; indeed, a number of serious and convincing arguments have been made in favor of legalized or decriminalized prostitution, as well as permissible payment to organ "donors." Moreover, the fact remains that we do allow subjects to be paid, and in that context, paid work is the most apt analogy.

Even those who accept the relevance of the comparison to workers, however, might be concerned that there is something fundamentally disrespectful about recasting the human research subject as human research worker, perhaps moving subjects from a special, revered category to the mundane ranks of the fast food employee or factory worker, for example. But note that the extension of various worker protections has been the result of the labor movement's attempts over centuries to improve the worker's plight and garner respect for the worker as a person rather than a widget. Thus, rather than treating the moniker "human research worker" as a demotion, it might even be considered a compliment.

Finally, to be absolutely clear, nothing herein is intended to suggest that repeat or professional research participation is a good thing. In most cases, it is decidedly not. So while some have expressed worry that extending greater protections to research subjects will make repeat participation more attractive, that fear can and should be addressed by the sorts of limitations on repeat participation discussed above, most importantly a subject registry. ${ }^{344}$ Even in the absence of a subject registry, however, it is important to recognize two things. First, repeat participation already occurs, and trying to discourage it via inadequate or inappropriate subject protections seems not only unfair, but callous and misguided. Second, the additional protections would apply not only to those subjects who consider research participation a job, but to all types of subjects, healthy and sick, paid and unpaid, one-time players and repeat enrollers. Thus, withholding protections to target one group of potential subjects is too blunt an instrument, and would ultimately leave many other subjects who are not engaged

343 See, e.g., Martha C. Nussbaum, "Whether from Reason or Prejudice": Taking Money for Bodily Services, 27 J. LEG. STUD. 693 (1998).

344 It will also likely be necessary to take additional steps to make sure that adequate enrollment can be achieved with these limitations, or to simply accept the consequence that some research may not be possible without the inclusion of repeat participants. 
in worrisome enrollment without valuable protections - protections that may make research participation itself more attractive to those who might otherwise have been unwilling to participate at all.

\section{CONCLUSION}

We often use the term "work" without really considering what it means what should be included and excluded from its reach. There are areas of clear agreement: the miner is working, the nurse is working, the bus driver, the teacher, the firefighter. And there are areas of contention: stay-at-home parents, prostitutes, reality TV stars - and research subjects. But instead of focusing on whether a particular activity should be classified as work, a job, an occupation, a profession, or something else, it is fruitful to ask a different question: why do we extend certain legal protections to those who are engaged in work? And if those reasons also apply to other activities, even when those activities seem to fall outside the traditional boundaries of "work," why should they be treated any differently? These are the questions that have driven this Article, and as a result, it is hoped that even those who reject the idea of research participation as work can see why certain worklaw protections ought to be extended to the research context.

Unlike the bioethicists who initiated this debate, this Article clarifies that a broad analogy between research subjects and workers does not actually suffice to demonstrate that subjects should be granted additional legal protections, since not all workers are protected by the law. And unlike the few legal decision-makers who have considered the employment status of research subjects, this Article goes beyond existing problematic legal distinctions to consider the ways in which subjects are like those workers who should be protected by the law. Ultimately, the HSR regulations should be revised such that all types of biomedical research subjects are free to accept unrestricted payment for their participation, eligible for a modified minimum wage, ensured no-fault compensation in the event of research injury, and protected in their efforts at concerted activity.

In the end, human subjects research may not be as special as it appears at first glance, nor the current regulatory scheme as protective as it might seem. The worker analogy draws these features into sharp relief, and should be pursued further, alongside other relevant comparisons, in order to develop the most consistent and justifiable legal and ethical approach to the acceptable involvement of human subjects in this socially important endeavor. 